\title{
WORKING paper

\section{Semi-Structural VAR and Unobserved Components Models to Estimate Finance-Neutral Output Gap}

\author{
Gábor Kátay ${ }^{1}$, Lisa Kerdelhué2, Matthieu Lequien ${ }^{3}$
}

December 2020, WP \#791

\begin{abstract}
The paper assesses the impact of adding information on financial cycles on the output gap estimates for eight advanced economies using two unobserved components models: a reduced form extended Hodrick-Prescott filter, and a standard semi-structural unobserved components model. To complement these models, a semi-structural vector autoregression model is proposed in which only supply shocks are identified. The accuracy of the output gap estimates is assessed based on their performance in predicting recessions. The models with financial variables generally produce more accurate output gap estimates at the expense of increased real-time volatility. While the extended Hodrick-Prescott filter is particularly appealing for its real-time stability, it lags behind the two semi-structural models in terms of forecasting performance. The vector autoregression model augmented with financial variables features the best in-sample forecasting performance, and it has similar real-time prediction capabilities to the semi-structural unobserved components model. Overall, financial cycles appear to be relevant in Japan, Spain, the UK, and - to a lesser extent - in the US and in France, while they are relatively muted in Canada, Germany, and Italy.
\end{abstract}

Keywords: Unobserved Components model, semi-structural VAR, output gap, financial cycle, sustainable growth, credit, house prices, advanced economies

JEL classification: C32, E32, E44, G01, O11, O1

\footnotetext{
${ }^{1}$ European Commission, Joint Research Centre (JRC), Via E. Fermi 2749, 21027 Ispra, Italy.gabor.katay@ec.europa.eu.

2 Aix-Marseille Univ., CNRS, EHESS, Centrale Marseille, AMSE and Banque de France, lisa.kerdelhue@gmail.com

3 Banque de France, Insee and PSE, matthieu.lequien@insee.fr

*We owe a special thank to Michel Juillard, Paolo Paruolo and Phurichai Rungcharoenkitkul for their careful reading of our manuscript and their many valuable comments and suggestions. We are grateful to Máté Tóth for sharing with us the codes of the semi-structural UCM in Melolinna and Tóth (2019) and the useful inputs he provided. We also thank the participants of the seminar at the Banque de France and at the European Central Bank, as well as the members of the Working Group on Econometric Modelling of the European System of Central Banks for the valuable ideas they raised in discussion. The views expressed in this paper are those of the authors and not necessarily those of the institutions the authors are affiliated with.
}

Working Papers reflect the opinions of the authors and do not necessarily express the views of the Banque de France. This document is available on publications.banque-france.fr/en 


\section{NON-TECHNICAL SUMMARY}

Potential output has been traditionally defined as the maximum level of economic activity attainable without triggering inflation and, in the same context, as the output linked to the level of employment that results in a non accelerating rate of inflation (Okun (1962)). The observed empirical regularity between output fluctuation and the cyclical pattern of inflation or unemployment has been for a long time the key ingredients in a large variety of models aiming to estimate the potential growth and the output gap. However, historical evidence suggests that unsustainable developments in the financial and housing sectors can generate large imbalances in the economy even if inflation and unemployment are low and stable (see e.g. White (2006); Hume and Sentance (2009); Schularick and Taylor (2012); Jordà et al. (2013)).

The paper assesses the impact of adding information on financial cycles on the output gap estimates for eight advanced economies using two unobserved components models: a reduced form extended Hodrick-Prescott filter, and a standard semi-structural unobserved components model. To complement these models, a semi-structural vector autoregression model is proposed in which only supply shocks are identified. The model is a modified version of Blanchard and Quah (1989) in which we exploit a wider set of information by using several (business and financial) cycle indicators without imposing further restrictions. The main idea is that since the potential growth builds upon supply shocks only, one set of constraints, stating that only supply shocks have permanent effects on the level of GDP in the long-run, is enough to recover the trend. We formally show that further restrictions are not needed as the different demand shocks are not interpreted and do not need to be separately identified.

The overall picture underlines the importance of taking financial variables into account when assessing the cyclical position of the economy. Independently of the model considered, the model augmented with financial variables proves to be consistently more effective in identifying unsustainable economic growth paths and in predicting recessions both in-sample and out-of-sample. In Spain, the United Kingdom and (to a much lesser extent) the United States, the credit and house prices boom in the run-up to the Great Recession is clearly identified, as well as a previous boom-bust in the United Kingdom during the 1980s-90s.

In Japan both credit and house prices booms at the turn of the 1990s led to the well-studied and prolonged crisis (the "Lost Decade"). In France the models signal a house prices boom during the 2000s, but there is no sign of a credit boom during the estimation period. Finally, the financial cycles appear relatively muted in Canada, Germany and Italy. 

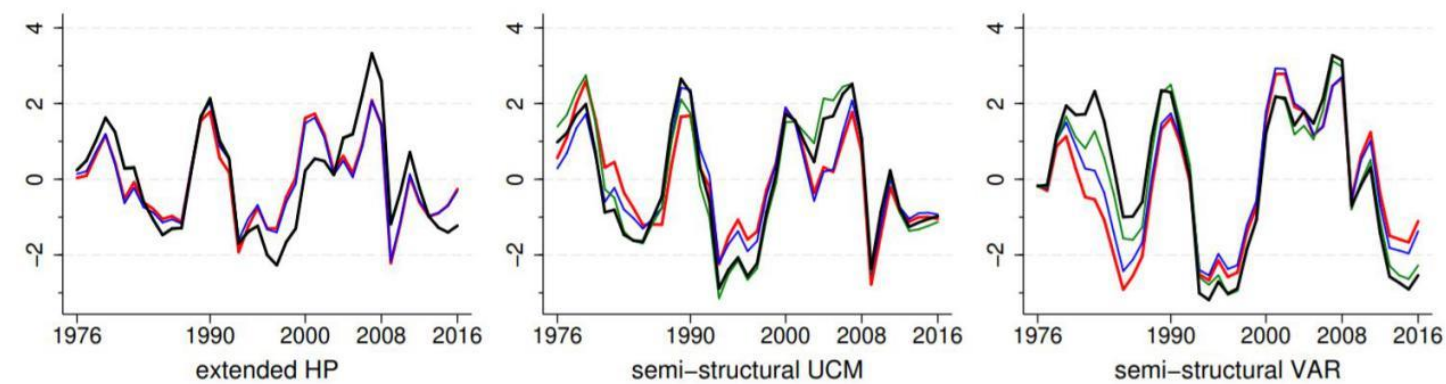

baseline

w/ credit

w/ house prices

w/ credit and house prices

Notes: This figure displays the output gap estimates for the extended HP filter (graph on the left), the semistructural UCM (middle) and the semi-structural VAR (right) for France. In each case, the baseline output gap (red) is shown along with the output gaps estimated with the addition of credit (blue), house prices (green) or both credit and house prices (black).

Sources: BIS, OECD, Authors' calculations.

\section{Modèles VAR semi-structurel et à composantes inobservables pour estimer l'écart de production financièrement neutre}

\section{RÉSUMÉ}

Ce document de travail évalue comment prendre en compte les cycles financiers dans l'estimation de l'écart de production pour huit économies avancées à l'aide de deux modèles à composantes inobservables: un filtre Hodrick-Prescott élargi et un modèle semi-structurel. Pour compléter ces modèles, nous proposons un modèle semi-structurel à vecteur autorégressif dans lequel seuls les chocs d'offre sont identifiés. La qualité de l'estimation de l'écart de production est évaluée à travers sa performance à prévoir les récessions. Les modèles avec variables financières produisent généralement des estimations de l'écart de production plus performantes au détriment d'une volatilité accrue en temps réel. Alors que le filtre Hodrick-Prescott élargi apparaît particulièrement attractif pour sa stabilité en temps réel, sa performance de prédiction est plus faible que celle des deux modèles semi-structurels. Le modèle à vecteur autorégressif augmenté avec des variables financières présente les meilleures performances de prévision ex-post et des performances similaires au modèle semi-structurel à composantes inobservables en temps réel. Dans l'ensemble, les cycles financiers apparaissent importants au Japon, en Espagne, au Royaume Uni et, dans une moindre mesure, aux Etats-Unis et en France, alors qu'ils sont relativement contenus au Canada, en Allemagne et en Italie.

Mots-clés : modèle à composantes inobservables; VAR semi-structurel; écart de production; cycle financier; croissance soutenable; crédit; prix immobiliers; économies avancées

Les Documents de travail reflètent les idées personnelles de leurs auteurs et n'expriment pas nécessairement la position de la Banque de France. Ils sont disponibles sur publications.banque-france.fr 


\section{Introduction}

Potential output has been traditionally defined as the maximum level of economic activity attainable without triggering inflation and, in the same context, as the output linked to the level of employment that results in a nonaccelerating rate of inflation (Okun (1962)). The observed empirical regularity between output fluctuation and the cyclical pattern of inflation or unemployment has been for a long time the key ingredients in a large variety of statistical filters, reduced form and general equilibrium models aiming to estimate the potential growth and the output gap. In such models, financial factors are either completely ignored or when included, their roles are limited to amplify the persistence of the shocks by slowing down somewhat the return of the economy to its steady state path (see e.g. Kiyotaki and Moore (1997); Bernanke et al. (1999); Woodford (2003)). However, historical evidence suggests that unsustainable developments in the financial and housing sectors can generate large imbalances in the economy even if inflation and unemployment are low and stable (see e.g. White (2006); Hume and Sentance (2009); Schularick and Taylor (2012); Jordà et al. (2013)).

The present paper is closely related to the recent empirical literature that extends traditional statistical output gap estimation techniques by incorporating financial cycle information. We start by conceptually and empirically comparing the performance of two types of popular unobserved components models (UCMs) in extracting both demand-driven traditional business cycles and financial cycles. The first UCM follows a novel "reduced form" approach pioneered by Borio et al. (2017) to estimate the "finance-neutral" output gap. In the "extended Hodrick-Prescott (HP)" model, pre-transformed financial cycle indicators are directly incorporated as additional covariates into the state-space representation of the univariate HP filter (model A) ${ }^{1}$. The second UCM is a simple semi-structural model featuring a Phillips curve, an Okun's law, a stochastic process relating output gap to capacity utilisation, and a separate block that relates financial cycles to the output gap (model B). Both the reduced form and the semi-structural UCMs augmented with financial variables are gaining increasing popularity $^{2}$, however, their relative advantages and limitations have not yet been empirically assessed.

To complement these previous models, we propose a new "semi-structural vector autoregression (VAR)" model with long-run restrictions (model C). The model is a modified version of Blanchard and Quah (1989) in which we exploit a wider set of information by using several (business and

\footnotetext{
${ }^{1}$ We also estimate a more flexible representation of this model, allowing for serial correlation of the output gap and introducing shocks to the level of the trend. However, the results from these two versions are very similar in all aspects. In other words, the additional flexibility of the dynamic multivariate filter compared to extended HP has very limited practical relevance. The results from this alternative specification are reported in Appendix B.

${ }^{2}$ Following Borio et al. (2017), several subsequent papers adopt the same (or very similar) methodology to recover the "sustainable growth" and the "finance-neutral output gap" (see e.g. Anvari et al. (2014); Odor and Kucserova (2014); Felipe et al. (2015); Krupkina et al. (2015); Maliszewski and Zhang (2015); Berger et al. (2015); Alberola-Ila et al. (2016); Amador-Torres et al. (2016); Grintzalis et al. (2017)). Bernhofer et al. (2014) adopt a more general statistical filtering technique proposed by Harvey and Jaeger (1993) to estimate the finance neutral output gap for several advanced and emerging EU countries. However, the basic concept of the method remains the same: financial cycle indicators are directly incorporated into output gap equation to help to better explain the cyclical movements of the output. Other papers extend the previous approach by incorporating financial information into semi-structural UCMs (see e.g. Rünstler and Vlekke (2018); Melolinna and Tóth (2019)). Our baseline semi-structural model is mostly based on Melolinna and Tóth (2019).
} 
financial) cycle indicators without imposing further restrictions. It extends the original BlanchardQuah model by combining two approaches. First, we include additional variables in the model and recover potential GDP using a minimal identification requirement with one set of constraints on the long-run effects of the shocks. The main idea is that since the potential growth builds upon supply shocks only, one set of constraints, stating that only supply shocks have permanent effects on the level of GDP in the long-run, is enough to recover the trend. We formally show that further restrictions are not needed as the other structural shocks are not interpreted and do not need to be separately identified. Furthermore, we show that the limited set of constraints used is the only one relevant for the decomposition of the output gap into contributions of the observables (see Andrle (2013) for a general explanation of the decomposition technique). With a different objective, similar semistructural VARs have been used by Bernanke and Mihov (1998), King et al. (1991) and Gali (1999).

Second, in the spirit of Borio et al. (2017), we directly include pre-transformed financial cycle indicators in the model instead of estimating or imposing theory-based cointegrating relations between GDP and the financial variables. In other words, we condition the output gap estimates only upon the short- and medium-run correlations between GDP and the indicator variables, while the fundamental, long-run relationships between GDP and financial variables are not explicitly modelled. As with the model of Borio et al. (2017), this "shortcut" allows us to keep the dimension of the model relatively small. On the other hand, in contrast to Borio et al. (2017), financial cycle indicators are treated as stochastic processes, i.e. shocks can affect the indicators without necessarily influencing the GDP.

Since the semi-structural VAR involves entirely different mechanisms to decompose the trend from the cycle than the two other UCMs, it can provide particularly informative additional insights compared to the other models. All the more so as the ability of the usual univariate or multivariate statistical filters to accurately differentiate between supply and demand shocks has recently been challenged. Coibion et al. (2018) argue that models relying on smoothing techniques gradually but persistently respond to all kinds of shocks to the GDP. The authors show that the Blanchard and Quah (1989) approach, which explicitly distinguishes between temporary and permanent shocks, does not suffer from this shortcoming, and can generate real-time estimates of potential output that are consistent with theoretical predictions much more successfully.

As a first step, we estimate the three "baseline" models for eight advanced economies - Canada (CA), France (FR), Germany (DE), Italy (IT), Japan (JP), Spain (ES), the UK, and the US - in which the cyclical pattern of the demand is captured by the unemployment rate, the capacity utilisation rate, and (in the semi-structural UCM) CPI inflation. As a second step, we test the implications of adding two additional variables that proved to be the most successful in capturing financial cycles: credit and house prices (see e.g. the literature review by Borio (2014)). The models are evaluated along several dimensions, such as the contribution of financial shocks to the estimated output gaps, the sensitivity of the results to pre-treatment methods, or the real time performance of the models. Finally, the overall accuracy of the estimated output gaps are assessed using receiver operating characteristic analysis based on their capabilities in predicting recessions.

The overall picture underlines the importance of taking financial variables into account when assessing the cyclical position of the economy. Independently of the model considered, the model 
augmented with financial variables proves to be consistently more effective in identifying unsustainable economic growth paths and in predicting recessions both in-sample and out-of-sample. In ES, the UK and (to a much lesser extent) the US, the credit and house prices boom in the run-up to the Great Recession is clearly identified, as well as a previous boom-bust in the UK during the 1980s-90s. In JP both credit and house prices booms at the turn of the 1990s led to the well-studied and prolonged crisis (the "Lost Decade"). In FR the models signal a house prices boom during the 2000s, but there is no sign of credit boom during the estimation period. Finally, the financial cycles appear relatively muted in CA, DE and IT. At the same time, our results suggest that financial information generally worsens the real-time stability of the models in both the short-run and the longer-run, sometimes even for countries without clear financial cycles identified ex-post (most notably for DE). In other words, the models with financial variables are generally more successful in signalling booms in real-time, but future revisions of the point estimates are larger.

The models under scrutiny have different properties along several important dimensions, which affect their practical efficiency in handling new information originating from the financial variables and thus their resulting finance-neutral output gap estimates. The approach proposed by Borio et al. (2017) is particularly appealing for its simplicity and real-time stability. Since the additional variables directly enter the output gap equation as deterministic covariates, there are only a few parameters to estimate and shocks to decompose and, as a consequence, the resulting output gap estimates are relatively less revised when new data become available. However, the extended HP filter generally lags behind the two semi-structural models in terms of forecasting performance, in particular when the models are augmented with financial variables. Moreover, the reduced form approach is sensitive to the (necessary) pre-transformation applied to the cycle indicators to make them stationary with zero mean. Without external validation of the resulting output gap estimates, it is often hard to choose between the different possible trend removal methods. Simply put, the extended HP filter can be viewed as the two-step version of the more complicated, semi-structural UCM: first, possible structural shocks to the indicator variables need to be removed; second, the correlation between the pre-filtered cycle indicator variables and the GDP is estimated, which helps to identify the output gap.

The semi-structural UCM provides a simultaneous estimation of these two steps. The difficulty of selecting the right pre-treatment method is therefore transformed into a difficulty of choosing the right structure and defining suitable Bayesian prior distributions on the parameters. By imposing a very light structure on the model and using standard prior beliefs about the parameters, the semistructural UCM produces, in general, more accurate finance-neutral output gaps with better early warning capabilities than the extended HP filter. However, the results for JP and - to a lesser extent - the US are good examples showing that solely relying on an arguably flexible and generally more capable approach may also lead to misleading conclusions. The semi-structural UCM for these two countries reveals significantly lower impact of financial cycles on the output gap estimates compared to the other models. In particular, both the semi-structural VAR and the reduced form model suggest that the Japanese finance-neutral output gap remains positive until 1998 following the asset price bubble's collapse in the early 1990s, whereas the output gap estimated using the semi-structural UCM already turns to negative - even though only temporarily - in 1993. The output gap remaining positive for a prolonged period of time after the bubble's collapse is arguably more in line with the Japanese 
"Lost Decade" paradigm. Similarly, the build-up of the financial bubble in the US was less forceful before the recent financial crisis according to the semi-structural UCM than the other models imply.

By taking advantage of its distinct trend-cycle decomposition technique, the semi-structural VAR provides valuable external validation of the results from the other models. This cross-check is particularly useful when the results from the other UCMs differ (such as for JP and the US) or the results are particularly sensitive to the priors imposed on the parameters of the model. Moreover, the semistructural VAR is generally more successful in accurately capturing macroeconomic and financial imbalances than the UCMs. The model features the best in-sample forecasting performance of recession probabilities among all three models, and it has similar real-time prediction capabilities to the semi-structural UCM and clearly superior to the extended HP filter. At the same time, this model also tends to react relatively more erratically to new observations included in the sample, especially when financial cycles are taken into account. The semi-structural VAR is also sensitive to the trend removal technique applied to the cycle indicators. However, contrary to the reduced form extended HP filter, the implied change in the output gap estimate following a change in the pre-filtering technique is less predictable.

In what follows, the two UCMs are briefly described (Section 2), and then the semi-structural VAR approach is presented in more detail (Section 3). Section 4 presents the data used for the estimations, the main estimation results, the decomposition of the output gap into the contribution of observables, the real-time performance and the forecasting accuracy analysis of the models. Finally, Section 5 summarises the main findings and puts them into a broader perspective.

\section{The unobserved components models}

\subsection{Extended Hodrick-Prescott filter}

Our simplest model has been advanced by Borio et al. (2017). A simple UCM, a univariate smooth trend model, which is the state-space representation of the famous HP filter, is augmented with additional variables $\left(z_{t}\right)$ :

$$
\begin{cases}y_{t}=y_{t}^{\star}+\gamma^{\prime} z_{t}+\varepsilon_{t} & \varepsilon_{t} \sim N\left(0, \sigma_{\varepsilon}^{2}\right) \\ y_{t}^{\star}=y_{t-1}^{\star}+g_{t-1}^{y} & \\ g_{t}^{y}=g_{t-1}^{y}+\xi_{t} & \xi_{t} \sim N\left(0, \sigma_{\xi}^{2}\right)\end{cases}
$$

where $y_{t}$ is the $\log$ of GDP, $y_{t}^{\star}$ is the $\log$ of the unobserved GDP trend and $g_{t}^{y}$ is the stochastic growth rate of the trend. $\varepsilon_{t}$ and $\xi_{t}$ are uncorrelated normally distributed random terms with variance $\sigma_{\varepsilon}^{2}$ and $\sigma_{\xi}^{2}$, respectively. The output gap is defined as the deviation of GDP from its sustainable path: $\hat{y}_{t}=y_{t}-y_{t}^{\star}$. The parameters of the model are estimated using maximum likelihood techniques and the gap is recovered using the Kalman filter.

A number of issues need to be addressed. To begin with, the stationarity of the business and financial cycle indicators (vector $z_{t}$ ) is a crucial yet in practice a rarely satisfied assumption. The 
coefficient of a non-stationary variable $z_{t}$ in small samples can receive a positive weight that will transmit a trend (or a non-zero mean) to the output gap. To overcome this problem, we follow the usual approach and pre-transform the series before plugging them into the model. A number of academic studies researching on financial imbalances de-trend the series using a HP filter with a smoothing parameter $\lambda=400,000$ (see e.g. Borio and Lowe (2002); Edge and Meisenzahl (2011); Detken et al. (2013); Borio et al. (2014b); Anundsen et al. (2016); Bauer and Granziera (2017); and the Basel III recommendation Committee (2010)). Consequently, only very low frequency cycles with average length above approximately 40 years are removed, well above the usual financial cycle frequencies. ${ }^{3}$ We follow the same procedure and de-trend the unemployment rate $\left(u_{t}\right)$, the credit $\left(c r_{t}\right)$ and the house prices $\left(h p_{t}\right)$ using a HP filter with the same value for $\lambda$. There is one exception: for DE, a HP filter with a lower smoothing parameter $(\lambda=1600)$ is used to better account for the downward trend of the unemployment rate following the introduction of the Hartz reforms. As for the capacity utilisation $\left(c_{t}\right)$, we simply remove the mean. The sensitivity of the results to various alternative low-frequency trend removal techniques will be discussed further in Sections 4.4 and $5 .{ }^{4}$

The second issue is the usual "pile-up" problem when maximum likelihood technique is employed: when the variation of trend growth rate $\sigma_{\xi}^{2}$ is small, the (maximum likelihood) estimate for $\sigma_{\xi}^{2}$ tends to be biased toward zero and as a result, the filter smooths potential output more than is necessary. The business cycle would then seem longer (Shephard (1993); Stock (1994); Stock and Watson (1998)). To avoid this, we follow the suggestion of Borio et al. (2017) and constrain the scaling factor $\lambda=\sigma_{\varepsilon}^{2} / \sigma_{\xi}^{2}$ so that the ratio of the variance of the output gap to the variance of the second differences of the trend - i.e. $\operatorname{var}\left(\hat{y}_{t}\right) / \sigma_{\xi}^{2}$ - is equal to 1600 , the standard value for quarterly data. This is achieved by recursively re-estimating the model until convergence.

Finally, the model suffers from two conceptual weaknesses. First, the extended HP filter might be too restrictive. The smooth trend model in eq. 1 with the above-mentioned constraint on the scaling factor assumes that the trend follows an integrated random walk. As such, the model does not allow for a level shock on potential output, since it allocates all permanent shocks to the potential output as shocks to the trend growth. Moreover, the model does not assume autocorrelation of the output gap. However, in practice, unit root tests on real GDP rather indicate integrated processes of order 1 (i.e. an I(1) process), rather than I(2) processes as assumed by the smooth trend model; and the output gap estimates produced by the filter are highly autocorrelated, which contradicts the formulation of the model (Grant and Chan (2017))..

Second and most importantly from the point of view of our exercise, the extended HP filter method may not be compatible with filtering out financial imbalances from output to obtain sustainable output because of the frequency discrepancy between financial and regular economic cycles. Using the usual value for the scaling factor, the extended HP filter is designed to filter out noise at the traditional business cycle frequency. Additional variables in $z_{t}$ will be significant determinant of the output

\footnotetext{
${ }^{3}$ The transfer function of the HP filter is given by (King and Rebelo (1993)): $h(\omega ; \lambda)=4 \lambda(1-\cos \omega)^{2} /(1+4 \lambda(1-$ $\cos \omega)^{2}$ ). If $\lambda=400,000, h(\omega ; \lambda)>0.5$ for $\omega>0.04$, which corresponds to about 39 years on quarterly data.

${ }^{4}$ Note that we did not seek to fully optimise the pre-treatment of the variables to achieve the most "credible" output gap estimates. Instead, we used rather standard pre-treatment techniques to illustrate the potential benefits and pitfalls of the different approaches.
} 
gap only if they can explain cyclical fluctuations at the traditional business cycle frequency (as, for example, the unemployment and the rate of capacity utilisation). However, financial variables have longer cycles and their correlation with GDP is expected at lower frequencies. A common business cycle covers 8 years, whereas on average the financial cycle is considerably longer, 15-20 years (see Claessens et al. (2012); Borio (2014); Rünstler and Vlekke (2018)).

To address these conceptual issues, we also estimate a more flexible version of the model which (i) allows for the serial correlation of the output gap, (ii) introduces shocks to the level of the trend and (iii) estimates the scaling factor rather than calibrates it. This model is similar in structure to the process describing the potential output and the output gap in the semi-structural UCM (model B in Section 2.2). It is also more in line with the assumptions used in the semi-structural VAR (model C in Section 3), in particular regarding the integration order of the GDP series. The model is described in details in Appendix B ("dynamic multivariate filter", model A'). The results from these two versions of the reduced form model are very similar: the correlation between the output gap estimates using these two methods, with or without financial variables, is very high, that is, more than 0.89 for all countries. In other words, the additional flexibility of the dynamic multivariate filter compared to extended HP has very limited practical relevance. Therefore, the results of the more flexible reduced form model are reported only in Appendix B.

\subsection{Semi-structural unobserved components model}

Our baseline model is similar to Melolinna and Tóth (2019), Anderton et al. (2014) (ECB), Benes et al. (2010) (IMF), and IMF-QPM model (Ermolaev et al. (2008), following Kuttner (1994)). It is a backward looking UCM with a Phillips curve, an Okun's law, and a stochastic process relating output gap to capacity utilisation. The baseline model includes four observable variables: log GDP $\left(y_{t}\right)$, inflation $\left(\pi_{t}\right)$ defined as the yearly log difference of the consumer price index (CPI), unemployment $\left(u_{t}\right)$ and capacity utilisation $\left(c_{t}\right)$.

Consequently, the model has four measurement equations with $x_{t}$ being the observable variable, $x_{t}^{\star}$ the unobservable trend and $\hat{x}$ the gap:

$$
x_{t}=x_{t}^{\star}+\hat{x}_{t}, x=\{y, \pi, u, c\}
$$

The decomposition of output into its potential and the output gap is described by the following three equations. The output gap is assumed to follow an $\mathrm{AR}(1)$ process, therefore featuring a serial correlation and experiencing transitory shocks. Potential output is defined as an I(1) process. Its stationary growth rate is an $\mathrm{AR}(1)$ revolving around its sample average. $\varepsilon^{y^{*}}$ and $\varepsilon^{g y}$ are permanent and temporary shocks to the potential output, respectively.

$$
\left\{\begin{array}{l}
\hat{y}_{t}=\alpha_{1} \hat{y}_{t-1}+\varepsilon_{t}^{\hat{y}} \\
y_{t}^{\star}=y_{t-1}^{\star}+g_{t}^{y}+\varepsilon_{t}^{y^{\star}} \\
g_{t}^{y}=\alpha_{2} \bar{g}^{y}+\left(1-\alpha_{2}\right) g_{t-1}^{y}+\varepsilon_{t}^{g y}
\end{array}\right.
$$


An Okun's law links unemployment and output gap. The unemployment gap includes a serial correlation and is supposed to be negatively correlated to the output gap. Potential unemployment is an I(1) process. Its first-difference follows an AR(1) process with zero mean.

$$
\left\{\begin{array}{l}
\hat{u}_{t}=\gamma_{1} \hat{u}_{t-1}-\gamma_{2} \hat{y}_{t}+\varepsilon_{t}^{\hat{u}} \\
u_{t}^{\star}=u_{t-1}^{\star}+g_{t}^{u}+\varepsilon_{t}^{u^{\star}} \\
g_{t}^{u}=\left(1-\gamma_{3}\right) g_{t-1}^{u}+\varepsilon_{t}^{g u}
\end{array}\right.
$$

An equation describing the relationship between capacity utilisation and output gap, in the spirit of the Okun's law, provides further identifying information. The capacity utilisation gap is assumed to be persistent and correlated with the output gap. Potential capacity utilisation is modelled as a driftless random walk.

$$
\left\{\begin{array}{l}
\hat{c}_{t}=\kappa_{1} \hat{c}_{t-1}+\kappa_{2} \hat{y}_{t}+\varepsilon_{t}^{\hat{c}} \\
c_{t}^{\star}=c_{t-1}^{\star}+\varepsilon_{t}^{c^{\star}}
\end{array}\right.
$$

A Phillips curve equation links output gap and inflation. The inflation gap is persistent (it is modelled as an AR(1) process) and is correlated with the output gap. Potential inflation is assumed to be a random walk without drift.

$$
\left\{\begin{array}{l}
\hat{\pi}_{t}=\beta_{1} \hat{\pi}_{t-1}+\beta_{2} \hat{y}_{t-1}+\varepsilon_{t}^{\hat{\pi}} \\
\pi_{t}^{\star}=\pi_{t-1}^{\star}+\varepsilon_{t}^{\pi}
\end{array}\right.
$$

The inclusion of the Phillips curve in the semi-structural model arguably provides additional information that is not present in the other models (A and C) tested. We add the Phillips curve to this model to be consistent with other similar UCMs used in the literature. However, we equally tested the model without the Phillips curve. Results from this model variant remain very close to our baseline findings. Similarly, we also tested a variant of the other models with inflation as an additional control. Our results confirm the findings of Borio et al. (2017) demonstrating that inflation "does very little to help condition output gap estimates". These additional results are available upon request.

The model with financial indicators corresponds to the baseline model augmented with financial variables $f_{t}=\{c r, h p\}$. They were added separately, before they were added together. First, a measurement equation decomposes the log of credit $(c r)$ and the log of house prices $(h p)$ into a trend and a cycle components:

$$
f_{t}=f_{t}^{\star}+\hat{f}_{t}, f \in\{c r, h p\}
$$

Second, the trend-cycle decomposition of $f_{t}$ is similar to that for output. The financial variable gap is linked to the output gap and is persistent. The trend of the financial variable is defined as I(1). Its stationary growth rate is an $\mathrm{AR}(1)$ process revolving around the sample average of $f$. 


$$
\left\{\begin{array}{l}
\hat{f}_{t}=\phi_{1} \hat{f}_{t-1}+\phi_{2} \hat{y}_{t}+\varepsilon_{t}^{\hat{f}} \\
f_{t}^{\star}=f_{t-1}^{\star}+g_{t}^{f}+\varepsilon_{t}^{f^{\star}} \\
g_{t}^{f}=\phi_{3} \bar{g}^{f}+\left(1-\phi_{3}\right) g_{t-1}^{f}+\varepsilon_{t}^{g f}
\end{array}\right.
$$

The model is estimated using a diffuse Kalman filter (Rosenberg (1973); De Jong (1991)) and Bayesian techniques. 5 Shocks are assumed to follow an inverse gamma function with infinite variance. The AR(1) parameters follow a beta distribution with prior mode 0.6 and prior variance of 0.25 . The rest of the priors follow gamma, beta or normal distributions. Details are presented in Appendix C.

\section{Semi-structural VAR with long-run restrictions}

Building on the seminal article by Blanchard and Quah (1989), we impose long-run restrictions to disentangle shocks to the trend influencing GDP in the long-term from shocks to the cycle with no influence on long-term GDP. We extend the original Blanchard-Quah model in two ways. First, instead of relying on two variables (GDP and an indicator of the business cycle such as the unemployment rate) and one long-run restriction (only the supply shock has a permanent effect on the level of GDP), we exploit a wider set of information by using several cycle indicators without imposing further restrictions. To avoid a fragile identification of all shocks through various long-run, short-run and/or sign restrictions, Blanchard and Quah (1989)'s original approach is used and only the same long-run constraints are imposed: only one of the structural shocks (the supply shock) impacts the GDP in the long run. This minimal identification requirement is sufficient to recover the supply shock, the potential growth, and thus the output gap. The other structural shocks (for simplicity, we call them demand shocks) are not interpreted.

Since the entire structure of the shocks is not identified, but only one of these shocks, the identification technique relates to semi-structural VARs (see Kilian and Lütkepohl (2017), Chapter 10). Similar semi-structural VARs in which only part of the structural shocks are correctly identified were used by, for example, Bernanke and Mihov (1998) to derive a new measure of monetary policy innovations based on various reserve market indicators; or King et al. (1991) to identify common permanent productivity shocks in output, consumption, and investment based on the "balanced growth" assumption. Our approach is the closest to the higher dimension model of Gali (1999), who identify technology shocks driving the productivity growth by using information on hours worked, money growth, inflation, and interest rates. Nevertheless, use of semi-structural VAR in the empirical literature remains scarce and, to our knowledge, it has never been used to recover the output gap.

Second, in the spirit of Borio et al. (2017), we directly include pre-treated cycle indicators in the model. This "shortcut" is particularly convenient when non-stationary financial variables are included

\footnotetext{
${ }^{5}$ We use the IRIS Toolbox, see: J. Benes, M. K. Johnston, and S. Plotnikov, IRIS Toolbox Release 20151016 (Macroeconomic modelling toolbox). The software is available at http://www.iris-toolbox.com
} 
in the model, since it allows us to avoid the need to estimate or impose cointegrating relationships between GDP and the financial variables. In practice, we use the same pre-transformed series as in our "extended HP filter" model (Section 2.1). ${ }^{6}$ However, in contrast to Borio et al. (2017), both the business and the financial cycle indicators enter the model as stochastic processes. Consequently, various shocks can affect the cycle indicators in the short and medium run without necessarily influencing the GDP. In other words, as opposed to the extended HP filter, shocks to the indicator variables are not necessarily directly transmitted to the output gap.

More formally and starting from the moving average (Wold) representation for the vector composed of growth $\Delta y_{t}$ and (stationary and demeaned) auxiliary variables $z_{t}\left(u_{t}, c_{t}\right.$, and in the augmented model, the two financial indicators: $c r_{t}$ and $h p_{t}$ ), the structural shocks $\left[\omega_{t}^{s}, \omega_{t}^{d}\right]$ need to be recovered from the innovations $\varepsilon_{t}$ :

$$
\left[\begin{array}{c}
\Delta y_{t} \\
z_{t}
\end{array}\right]=C(L) \varepsilon_{t}=A(L) \omega_{t}=A(L)\left[\begin{array}{c}
\omega_{t}^{s} \\
\omega_{t}^{d}
\end{array}\right]
$$

Blanchard and Quah (1989) only use information from one macroeconomic variable beyond GDP: in their model $z_{t}$ is a variable (unemployment) instead of a vector. Therefore, they separate two shocks into a demand disturbance $\left(\omega_{t}^{d}\right)$ and a supply disturbance $\left(\omega_{t}^{d}\right)$. To achieve this, one constraint is enough: the demand disturbance has no effect on GDP in the long run.

In contrast, we separate one supply shock from many other demand shocks by using several indicator variables $\left(z_{t}\right.$ and $\omega_{t}^{d}$ are column vectors with $n$ elements). Noting $A(L)=\sum_{i=0}^{\infty} A_{i} L^{i}$ and $C(L)=\sum_{i=0}^{\infty} C_{i} L^{i}$, and given that $C_{0}=I$, then $A_{0} \omega_{t}=\varepsilon_{t}$ and $A_{i}=C_{i} A_{0}$. Since $E\left(\omega_{t}\right)=0$, $E\left(\omega_{t} \omega_{t}^{\prime}\right)=I_{n+1}$ and $\varepsilon_{t} \varepsilon_{t}^{\prime}=A_{0} \omega_{t} \omega_{t}^{\prime} A_{0}^{\prime}$, the variance-covariance matrix $V(\varepsilon)$ is given by:

$$
V(\varepsilon)=A_{0} A_{0}^{\prime}
$$

$A(1) \omega_{t}=C(1) A_{0} \omega_{t}$ is the long-term accumulated response of the GDP growth and the auxiliary variables to the structural shocks $\omega_{t}$. It can therefore be imposed that only the supply shock (that we choose as the first component of $\omega_{t}$ ) has an impact on the level of GDP in the long run:

$$
A(1)=C(1) A_{0}=\left[\begin{array}{c|c}
a_{11} & 0_{1 \times n} \\
\hline A_{n \times 1} & Z_{n \times n}
\end{array}\right]
$$

The $n$ zeroes from the first line in eq. 11 impose that only the supply shock $\omega_{t}^{s}$ is allowed to impact GDP in the long-run. These are the constraints that matter to separate the supply shock from the other shocks.We further impose $n \times(n-1) / 2$ arbitrary constraints on the matrix $Z$ to be able

\footnotetext{
${ }^{6}$ Blanchard and Quah (1989) also stress the necessity of some form of pre-treatment applied to the indicator series. The authors discuss how to deal with the time trend in unemployment. They compare the results obtained with raw or de-trended unemployment series, and show that the results obtained using either of the two series are qualitatively similar.
} 
to identify $A_{0}$ and therefore all of the structural shocks (e.g. by imposing $Z$ to be lower triangular), ${ }^{7}$ but crucially the potential growth (i.e. growth stemming from the supply shock only) and therefore the output gap do not depend on these constraints. To put it differently, the constraints on $Z$ split the innovations between the various demand shocks, but the output gap is the same whatever the construction of the demand shocks. For the same reason, the contribution of each variable to potential growth does not depend on these additional restrictions set on $Z$ : this contribution reflects the part of the variable having an impact on long-term GDP. How the rest of this variable - the part with no impact on long-term GDP - is split between the different demand shocks is therefore irrelevant, as shown below.

Let's denote $\left[\begin{array}{c}\omega_{t}^{s} \\ 0_{n \times 1}\end{array}\right]=\left[\begin{array}{c|c}1 & 0_{1 \times n} \\ \hline 0_{n \times 1} & 0_{n \times n}\end{array}\right] \omega_{t}=B \omega_{t} . y_{t}^{\star}$ is estimated by setting all structural shocks $\omega_{t}^{d}$ to 0 :

$$
\begin{aligned}
{\left[\begin{array}{c}
\Delta y_{t}^{\star} \\
z_{t}^{\star}
\end{array}\right] } & =A(L) B \omega_{t}=C(L) A_{0} B \omega_{t}=C(L) A_{0} B A_{0}^{-1} \varepsilon_{t}=C(L) C(1)^{-1} A(1) B A(1)^{-1} C(1) \varepsilon_{t} \\
& =C(L) C(1)^{-1}\left[\begin{array}{c|c}
a_{11} & 0_{1 \times n} \\
\hline A_{n \times 1} & Z_{n \times n}
\end{array}\right]\left[\begin{array}{c|c}
1 & 0_{1 \times n} \\
\hline 0_{n \times 1} & 0_{n \times n}
\end{array}\right]\left[\begin{array}{c|c}
\frac{1}{a_{11}} & 0_{1 \times n} \\
\hline-\frac{1}{a_{11}} Z_{n \times n}^{-1} A_{n \times 1} & Z_{n \times n}^{-1}
\end{array}\right] C(1) \varepsilon_{t} \\
& =C(L) C(1)^{-1}\left[\begin{array}{c|c|c}
1 & 0_{1 \times n} \\
\hline \frac{1}{a_{11}} A_{n \times 1} & 0_{n \times n}
\end{array}\right] C(1) \varepsilon_{t}
\end{aligned}
$$

$C(L)$ and $C(1)$ (inverse of the VAR) depend only on reduced-form parameters of the VAR. Futhermore, the parameters $a_{11}$ and $A_{n \times 1}$ in $A(1)$ are identified by the equations 10 and 11 without requiring the knowledge of $Z$ :

$$
\begin{aligned}
A(1) A(1)^{\prime} & =\left[\begin{array}{c|c}
a_{11}^{2} & a_{11} A_{1 \times n}^{\prime} \\
\hline a_{11} A_{n \times 1} & A_{n \times 1} A_{1 \times n}^{\prime}+Z_{n \times n} Z_{n \times n}^{\prime}
\end{array}\right] \\
& =C(1) A_{0} A_{0}^{\prime} C(1)^{\prime}=C(1) V(\varepsilon) C(1)^{\prime}
\end{aligned}
$$

Given that none of the matrices involved in the last line of eq. 12 depend on $Z$, the estimation of potential growth $\Delta y_{t}^{\star}-$ and that of $z_{t}^{\star}-$ is independent of the exact specification of $Z$.

We then compute the output gap $\hat{y}_{t}$ as $y_{t}-y_{t}^{\star}=\sum_{t_{0}=1}^{t} \Delta y_{t}-\sum_{t_{0}=1}^{t} \Delta y_{t}^{\star}-\overline{\sum_{t_{0}=1}^{t} \Delta y_{t}-\sum_{t_{0}=1}^{t} \Delta y_{t}^{\star}}$, with $\overline{\sum_{t_{0}=1}^{t} \Delta y_{t}-\sum_{t_{0}=1}^{t} \Delta y_{t}^{\star}}$ being the mean of the cumulated difference between growth and potential growth. This latter term ensures that the output gap has mean zero. The output gap $\hat{y}_{t}$ does not depend on the matrix $Z$ because neither $\sum_{t_{0}=1}^{t} \Delta y_{t}$ nor $\sum_{t_{0}=1}^{t} \Delta y_{t}^{\star}$ depends on it.

\footnotetext{
${ }^{7}$ The identification of $A_{0}$ requires $(n+1)^{2}$ constraints. Equation 10 yields $(n+1) \times(n+2) / 2$ restrictions, and the first line of $A(1)$ in eq. 11 imposes an additional $n$ constraints. The remaining $n \times(n-1) / 2$ exclusion restrictions are placed on the matrix $Z$.
} 
Finally, note that the contribution of one variable to the output gap is therefore simply the cumulative difference between its contribution to growth and its contribution to potential growth. Replacing $\varepsilon_{t}$ with $C(L)^{-1}\left[\Delta y_{t}, z_{t}\right]^{\prime}$ in eq. 12 , it can be seen that the decomposition of the output gap into the observables does not depend on the matrix $Z$ either.

This semi-structural VAR has some appealing advantages: it imposes a very light structure on the data, thus "lets the data speak". In particular, since we do not need to identify all structural shocks, the identifying assumption requires only minimal restrictions. Although the series must be stationary and must therefore be transformed before the estimation (we perform the same pre-transformation as in the reduced-form models), the auxiliary variables are still treated as stochastic processes. Finally the estimation is straightforward: we use the Full Information Maximum Likelihood (FIML) procedure and the scoring method described in Amisano and Giannini (1997).

\section{Results}

\subsection{Data source}

We use quarterly and seasonally adjusted data for eight advanced economies: CA, FR, DE, IT, JP, ES, the UK and the US. We took the longest publicly available series for each country. Start dates range from $1968 \mathrm{q} 4$ to $1985 \mathrm{q} 1$ depending on the country, while the end date is always $2016 \mathrm{q} 4 .{ }^{8}$ Gross domestic product, consumer price index and the rate of capacity utilisation are obtained from the OECD Main Indicators database. The unemployment rate comes from the OECD Economic Outlook database. Total credit to the non-financial sector comes from the BIS total credit statistics database. Real house prices are calculated using house prices from national sources, BIS Residential Property Price database and the Consumer Price Index from the OECD. ${ }^{9}$ The credit and house prices series were seasonally adjusted. Further details on the data can be found in the Appendix.

\subsection{Main results}

Figure 1 shows, for each country and each model, the estimated output gaps without financial information (baseline, red line), and augmented with credit (blue line), house prices (green line) or both (black line). The differences between the augmented and the baseline models are the impacts of introducing financial cycle indicators into the models on the output gap estimates. As shown in more detail in the next section, these differences - with some exceptions outlined in the paper - are highly correlated with the contributions of the financial variables to the output gap. Therefore, the differences in the output gap estimates with and without financial variables can safely be interpreted as signs of financial imbalances not reflected in the baseline output gaps. We start by discussing and

\footnotetext{
${ }^{8}$ The estimation period begins in 1968q4 for IT, 1970q1 for CA, DE and the US, 1976q1 for FR, 1976q1 for ES, $1978 \mathrm{q} 1$ for JP and 1985q1 for the UK.

${ }^{9}$ To get longer time series, we use other data sources for the rate of capacity utilisation for CA and JP. See Appendix A for details.
} 
comparing the results obtained using the two UCMs, then we turn our attention to the semi-structural VAR and show how it shapes our understanding of financial cycles and their interactions with GDP.

The graphs clearly show that the baseline output gap estimates from the two UCMs are close to each other for all countries. ${ }^{10}$ The models generally produce economically plausible output gap estimates. The economic downturn starting with the 2007-08 financial crisis - and further aggravated by the subsequent debt crisis for IT and ES - appears as the worst crisis in our sample for most countries. The only exception is CA, for which it turned out to be relatively benign, especially so in comparison with its severe crisis in the 1980s.

Adding financial information generally drives the two UCMs' output gap estimates apart. Most notably, the UCMs seem to use the additional information provided by the financial variables differently in the case of JP: the extended HP filter reveals a significantly higher and more prolonged impact of the Japanese financial bubble of the 1990s than the semi-structural UCM. The former model suggests that the finance-neutral output gap remains positive until 1998, whereas the latter model already indicates - even though only temporarily - a negative output gap in 1993.

The results from the UCMs are also divergent for the UK: while the semi-structural UCM clearly shows the impact of both credit and housing bubbles in the late 1980s and in the 2000s, the extended HP filter only signals the effects of house prices cycles. Similarly, the extended HP filter points towards a somewhat more important role of housing bubbles in FR and credit bubbles in DE during the years preceding the crisis.

Turning to the semi-structural VAR, results show no sign of systematic differences between this model and the UCMs that could be summarized in a single, clear message. Instead, the example of the 8 countries illustrate distinct cases, highlighting specific features of the semi-structural VAR and diverse aspects of its contribution to the overall picture.

Although the baseline semi-structural VAR draws a similar picture than the UCMs for most countries, there are also some marked differences. In particular, the model indicates a higher pre-crisis output gap compared to the other baseline models for FR and ES. Conversely, the semi-structural VAR without financial variables seems to be unable to pick up the high volatility in output around the outbreak of the crisis in the UK and it generates relatively less informative high frequency output gap fluctuations for DE.

The model with financial variables reinforces the findings from the extended HP filter and somewhat contradicts the findings from the semi-structural UCM in the case of JP and (to a lesser extent) the US. More precisely, both the semi-structural VAR and the reduced form model suggest that the Japanese finance-neutral output gap remains positive for a prolonged period of time after the asset price bubble's collapse in the early 1990s, more in line with the Japanese "Lost Decade" paradigm. Similarly, the build-up of the financial imbalances in the US before 2007 seems to be more forceful than the semi-structural UCM implies.

\footnotetext{
${ }^{10}$ The correlation between the output gaps from the extended HP filter and the semi-structural UCM exceeds 0.82 for all countries.
} 
On the other hand, the semi-structural VAR gives credit to the semi-structural UCM in the case of the UK, suggesting that both credit and house prices cycles have been important sources of macroeconomic fluctuations in the country. Finally, the semi-structural VAR gives a similar general picture on CA and IT to the other models, showing no clear sign of impact of financial cycles on GDP. The only country for which the semi-structural VAR provides less credible or informative output gap estimates compared to the other models, either with or without financial variables, is DE.

An overall picture emerges from the results of all the models combined. Our findings are in line with previous work that documents the exceptional resilience of the Canadian economy in the midst of the global financial crisis (Bordo et al. (2015); Haltom (2013)). The financial cycles appear to be relatively muted in DE (as in Rünstler and Vlekke (2018)) and in IT as well. The models signal a house prices boom in FR during the 2000s. Both credit and house prices boom in JP at the turn of the 1990s, leading to a well-studied prolonged crisis (see e.g. Bayoumi (2001)). In the US, the credit and house prices boom in the run-up to the Great Recession is clearly visible. Corroborating the findings of Rünstler and Vlekke (2018), our results indicate that ES and the UK have suffered from the largest and the longest financial cycles.

Figure 1: Output gap estimates
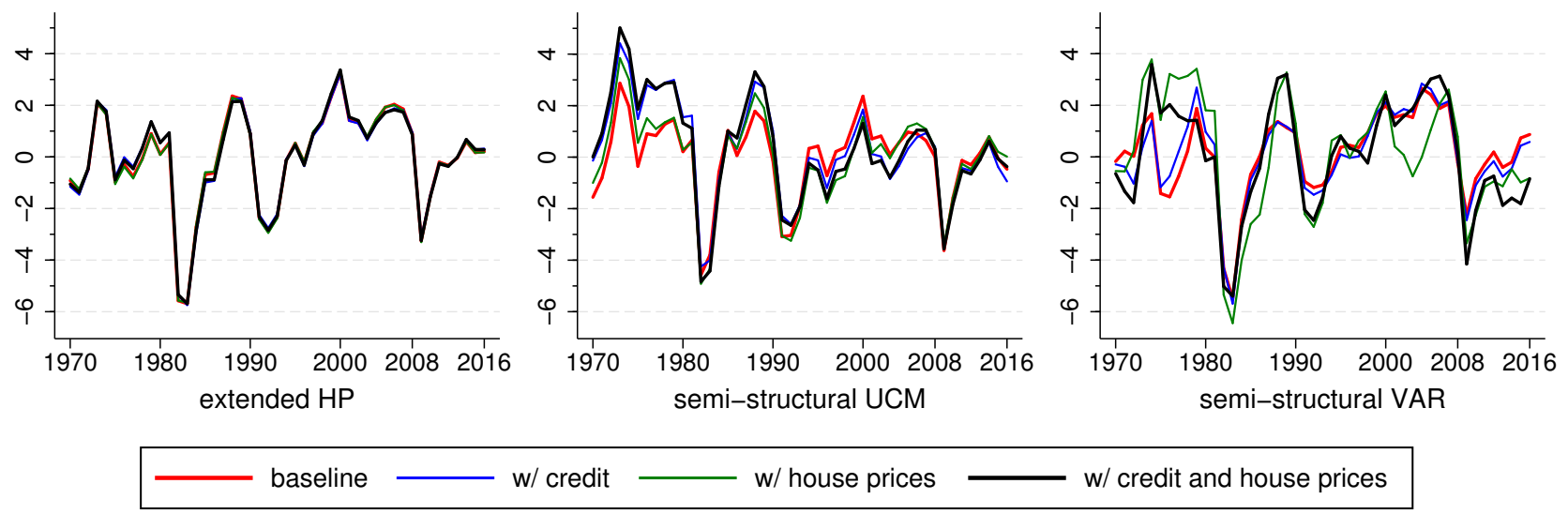

(a) Canada
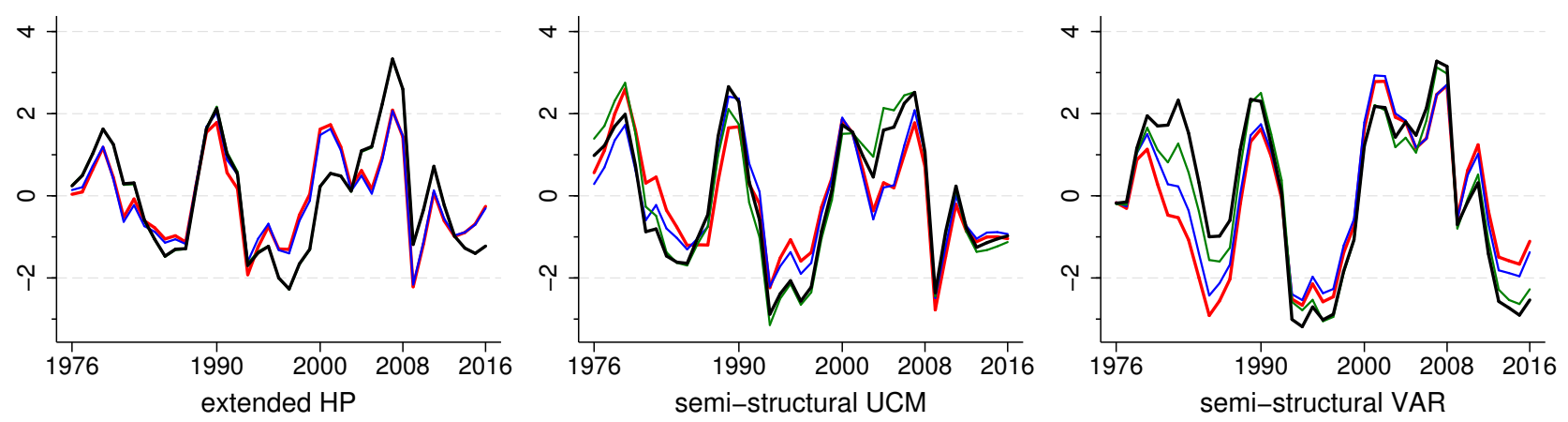

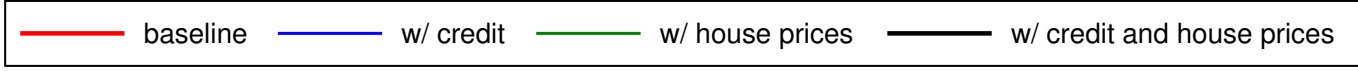

(b) France 

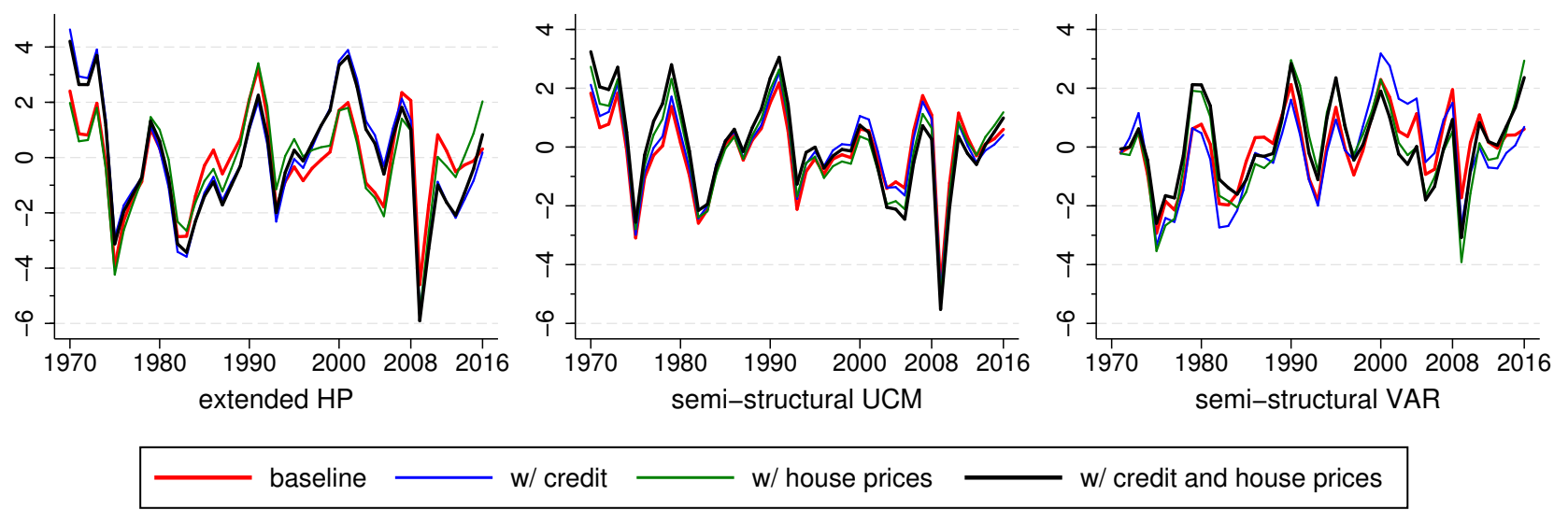

(c) Germany
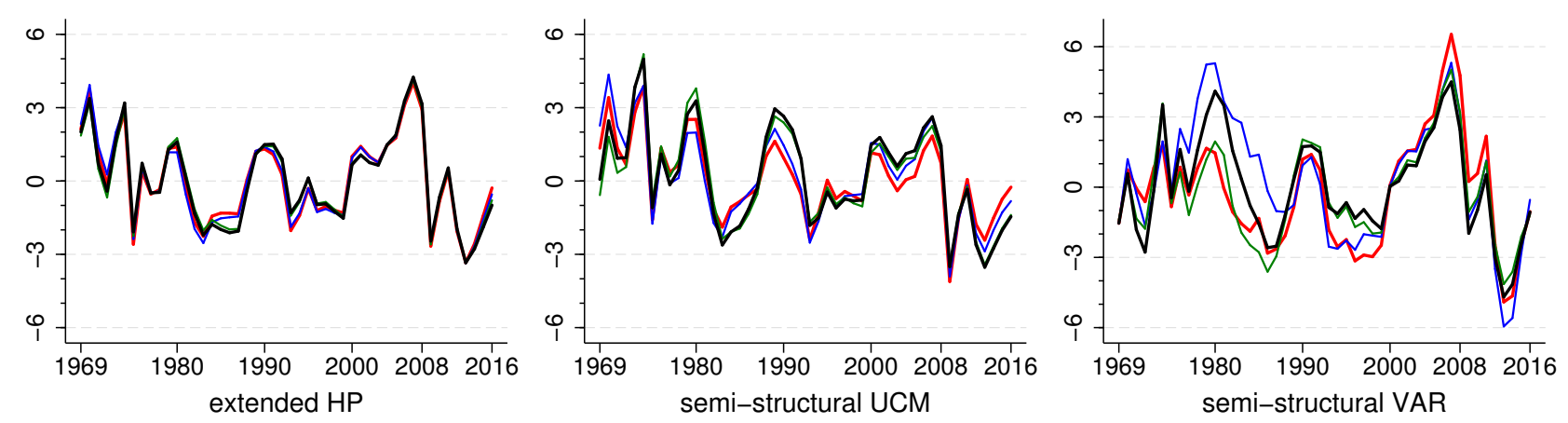

$$
\text { baseline } w \text { w/ credit w/ house prices } \longleftarrow \text { w/ credit and house prices }
$$

(d) Italy
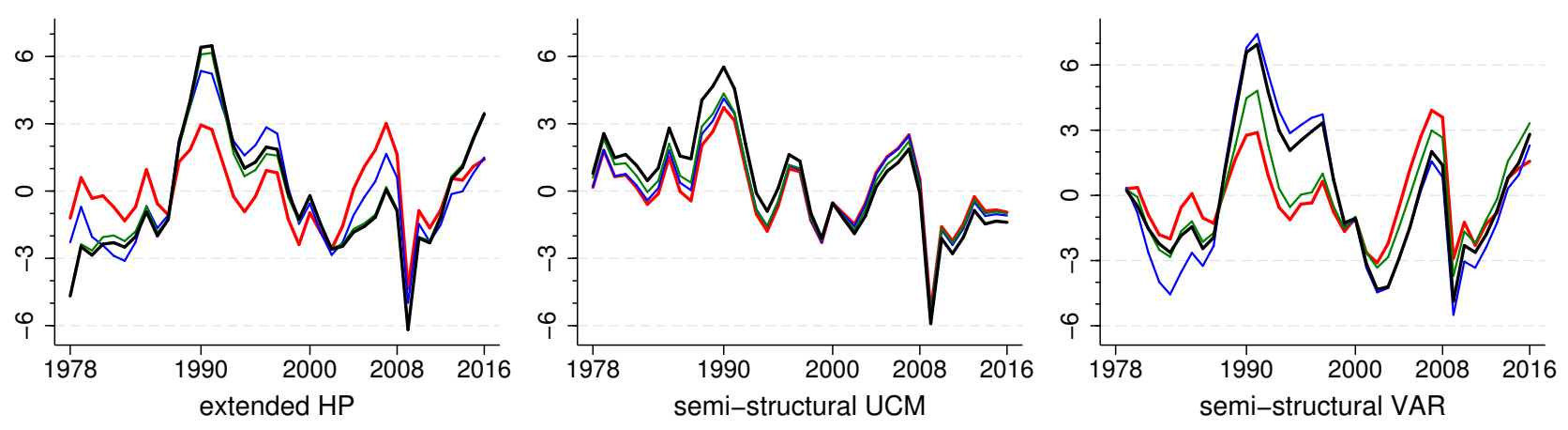

baseline w/ credit

w/ house prices

w/ credit and house prices

(e) Japan 

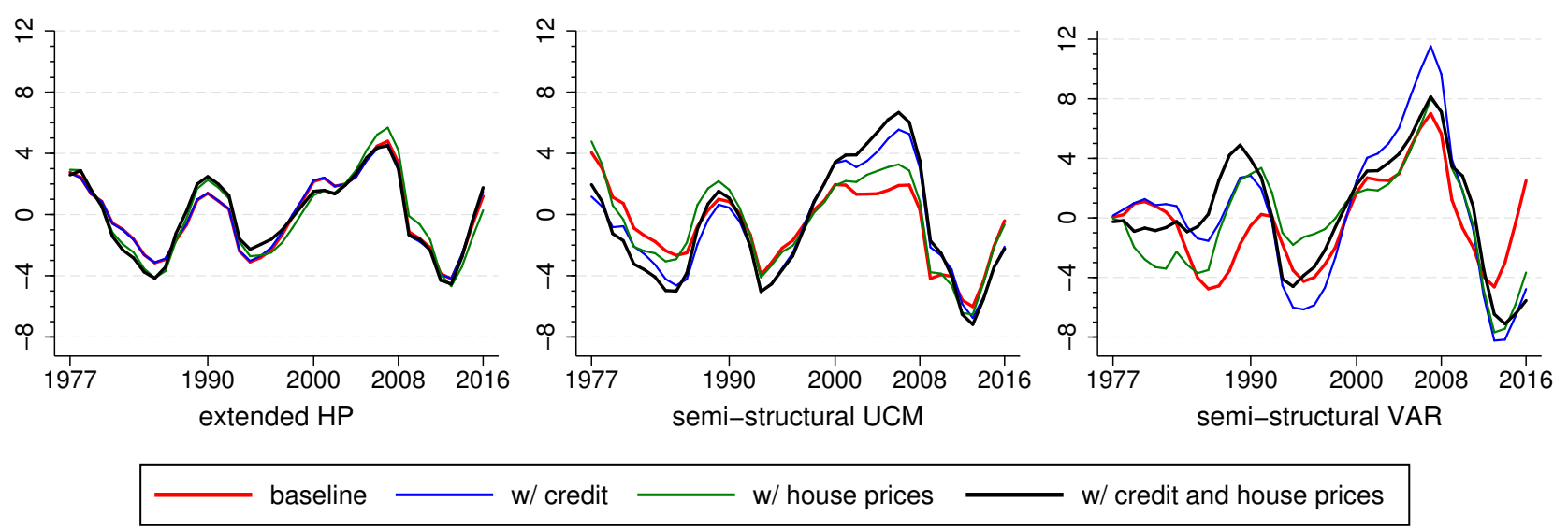

(f) Spain
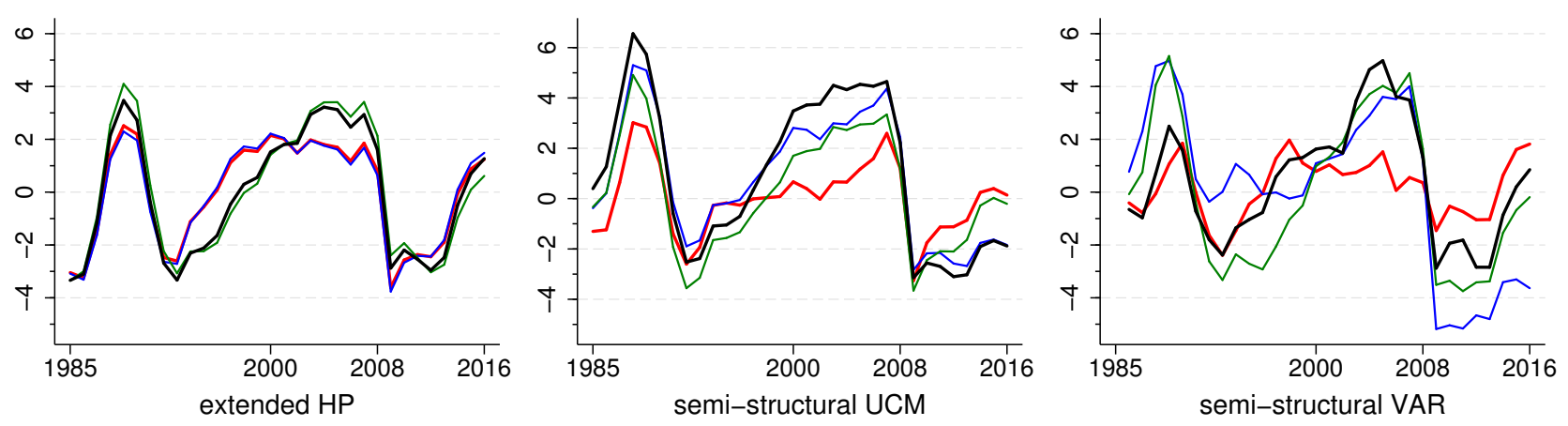

\begin{tabular}{|c|c|c|c|}
\hline _ baseline & w/ credit & w/ house prices & w/ credit and house prices \\
\hline
\end{tabular}

(g) UK
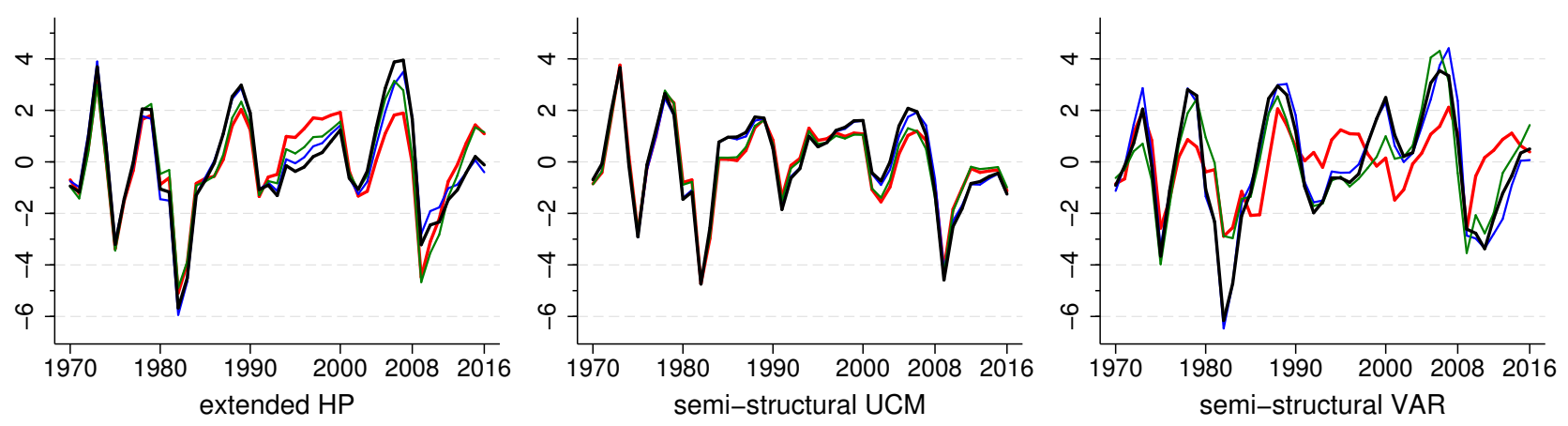

baseline

w/ credit

w/ house prices

w/ credit and house prices

(h) US

Notes: Figures 1(a) to 1(h) display the output gap estimates for the extended HP filter (graph on the left), the semistructural UCM (middle) and the semi-structural VAR (right) for each country. In each case the baseline output gap (red) is shown along with the output gaps estimated with the addition of credit (blue), house prices (green) or both credit and house prices (black). 


\subsection{Decomposition of the output gap into the contribution of observables}

Changes in the output gap estimates triggered by the introduction of financial variables do not necessarily signal financial imbalances. For instance, the parameters of the model might change with a new variable in the model. As a result, the estimated output gap might change even if the direct influence of the variable on the GDP is limited or, inversely, the new output gap might be close to the baseline estimate even if the influence of the variable is important.

To assess the direct influence of the financial variables on the output gap, we decompose the gap estimates into the contribution of each variable. All of the models considered can be formulated as linear filters: the output gap can be written as a moving average of the observables. Therefore, the output gap can be decomposed exactly into the contribution of each observable. It is different from the more widely used shock decomposition: the contributions of the observables assess the influence of the variables themselves - not their shocks - on the estimated output gap. The technique is described in Andrle (2013). Section 3 gives additional details about the methodology applied to the semi-structural VAR.

For each country and each model, we compare the contribution of credit (in the model with only credit), house prices (in the model with only house prices), or from both credit and house prices (in the model with both financial variables), with respectively the "credit deviation" (difference between the output gap from the model with only credit and the baseline output gap), the "house prices deviation", and the "credit and house prices deviation" (difference between the output gap from the model with both credit and house prices and the baseline output gap). Figure 2 describes the correlations for each country and model between these deviations from the baseline estimates and the contributions of the financial variables.

These correlations are generally very high, especially for the UCMs. The extremely low correlations that appear for the credit for CA and FR and for the house prices for IT in the case of the semi-structural VAR can be disregarded: the variables have virtually no influence on the output gap, so their contribution is close to 0 , which makes the correlation rather meaningless (see Figures 1(a), (b) and (d)). On the other hand, the low correlation of the contribution of house prices and the house price deviation (as defined in the previous paragraph) for the semi-structural VAR for FR indicates that the baseline model is relatively less robust to the introduction of house prices and, therefore, the results should be interpreted with more caution. The same problem arises to a much lesser extent with the introduction of house prices into the semi-structural VAR model for ES and JP.

Overall, measuring the deviations from the baseline for the large majority of the countries and models is roughly equivalent to computing the contribution of the financial variable(s) to the output gap estimates. The differences between the augmented and the baseline estimates can therefore be interpreted as signs of financial imbalances not reflected in the baseline output gaps. For example, if 
the introduction of credit translates into a (much) higher output gap, the contribution from credit will be positive (and large). Both measures point to the same (large) credit boom. ${ }^{11}$

Figure 2: Correlation between deviations from the baseline and the contributions of financial variables

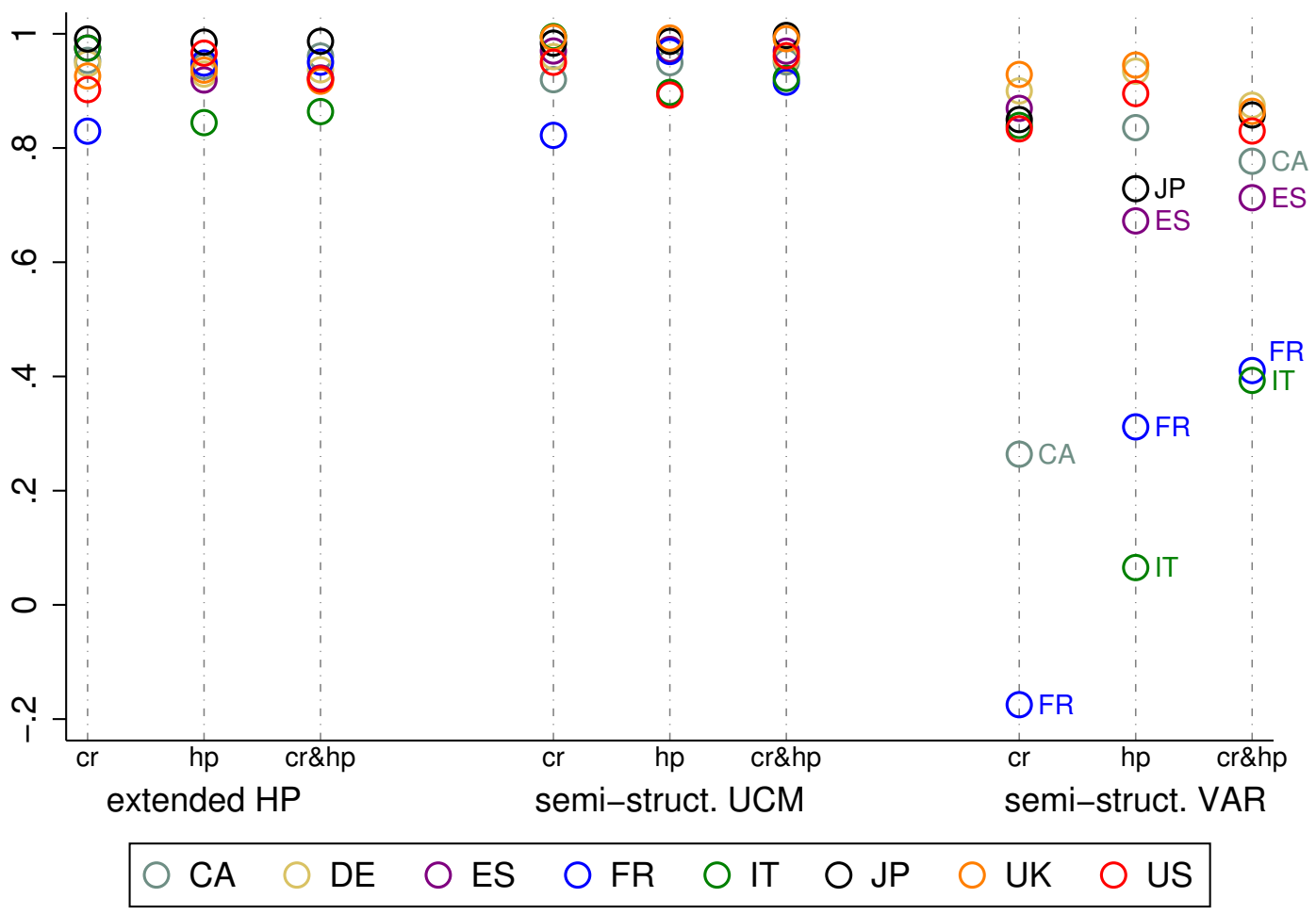

Notes: For each model and each country, we plot the correlation between (1) the contribution of credit ("cr", in the model with only credit), house prices ("hp", in the model with only house prices), or from both credit and house prices ("cr\&hp”, in the model with both financial variables) and (2) the respective "credit deviation" (difference between the output gap from the model with only credit and the baseline output gap), "house prices deviation", and "credit and house prices deviation". The correlation measures below 0.8 are labelled with the country code.

\subsection{Sensitivity of the results to pre-treatment methods}

The sensitivity of the results to the pre-transformation technique applied to the cycle indicators is tested by re-estimating both the extended HP filter and the semi-structural VAR with alternative pretreatment methods. Instead of relying on HP-filtered variables, we de-trend each element of $z_{t}$ (both the business cycle and financial cycle indicators) by regressing out the second or third order polynomial trend. As a third alternative, we feed the models with the cyclical part of the indicator variables obtained from the semi-structural UCM $\left(\hat{u}_{t}, \hat{c}_{t}, \hat{c r}{ }_{t}, \hat{h p_{t}}\right)$.

\footnotetext{
${ }^{11}$ The visual inspection of the graphs comparing the contribution of each financial variable and the deviation in the output gap due to the inclusion of the financial variable into the model confirms this finding. These graphs are not presented in this paper for brevity reasons, but are available from the authors upon request.
} 
Table 1 presents the standardized mean deviations (SMDs) of the input variables and the resulting finance-neutral output gap estimates with respect to the reference model with HP-filtered indicators. More precisely, we compute the average deviations as $\sum_{m=1}^{M} \sum_{t=t_{0}}^{T} \frac{1}{M\left(T-t_{0}+1\right)} \frac{\left|z_{i t}^{m}-z_{i t}^{\text {ref. }}\right|}{\sigma_{i}^{\text {ref. }}}$, with $z_{i t}^{m}$ are the indicator variables from the alternative pre-treatment method $m=\{1, \ldots, M\}$ of country $i$ and $z_{i t}^{\text {ref. }}$ are the reference HP-filtered indicators with standard deviations $\sigma_{i}^{\text {ref. }}$. SMDs of the corresponding output gaps are calculated in a similar way.

All countries and all alternative pre-filtering methods combined, the SMD of the estimated output gap with respect to the reference model (HP-filtered indicators) is 24 per cent of the overall standard deviation of the output gaps for the extended HP model and 50 per cent for the semi-structural VAR. These numbers correspond to an average deviation of 0.5 percentage points and 1.2 percentage points for the respective models. That is, the semi-structural VAR is more sensitive to the input indicators than the extended HP model.

The order of magnitude of the SMDs of the output gaps is in accordance with the SMDs of the indicator variables. On average, with an overall SMD of 0.58 , the unemployment gap is the most affected by the choice of the pre-treatment method. This is especially true for DE, the country for which a lower smoothing parameter is used in the reference model in order to account better for the relatively rapid changes in the structural unemployment rate following the Hartz reforms (see Section 2.1). At the other extreme, the least impacted variable is the capacity utilisation.

The first two columns of Table 2 attempt to explain the differences in the results obtained using various pre-treatment methods by differences in cycle indicators using a simple linear model. We pool all countries and all pre-treatment methods (de-trended by second or third order polynomials; and the cycle indicators from the semi-structural UCM), we calculate the differences with respect to our reference method and regress the output gap differences on differences in the indicator measures using ordinary least squares. As shown in the first column, for the extended HP model, 66 per cent of the variation in the estimated output gaps can be explained by the variations in input indicators. These results indicate that the cycle indicators directly transmit to the estimated output gap to a large extent. This is not the case for the semi-structural VAR: while the model is also sensitive to the pretreatment method applied, the change in the resulting output gap estimates is much less predictable. These results hold true when more lags are added to the model: even with 10 lags, the adjusted R2 is 0.68 in the case of the extended HP model and 0.02 in the case of the semi-structural VAR. When the parameters of the explanatory variables are allowed to vary by country, the adjusted R2 increases to 0.93 for the extended HP model and to 0.33 for the semi-structural VAR. ${ }^{12}$

\footnotetext{
${ }^{12}$ These additional results are not presented in the paper, but are available from the authors upon request.
} 
Table 1: Standardised mean deviations w.r.t. the model with HP-filtered indicators

\begin{tabular}{lcccccc}
\hline & $\hat{u}_{t}$ & $\hat{c}_{t}$ & $\hat{c r}_{t}$ & $\hat{h p_{t}}$ & $\hat{y}_{t}^{\text {extended HP }}$ & $\hat{y}_{t}^{\text {semi-struct. VAR }}$ \\
\hline Canada & 0.35 & 0.20 & 0.53 & 0.28 & 0.25 & 0.31 \\
France & 0.40 & 0.12 & 0.11 & 0.21 & 0.12 & 0.20 \\
Germany & 1.71 & 0.20 & 0.37 & 0.42 & 0.31 & 0.75 \\
Italy & 0.35 & 0.26 & 0.38 & 0.28 & 0.16 & 0.50 \\
Japan & 0.77 & 0.23 & 0.41 & 0.32 & 0.49 & 0.63 \\
Spain & 0.28 & 0.17 & 0.25 & 0.31 & 0.15 & 0.60 \\
UK & 0.45 & 0.23 & 0.62 & 0.21 & 0.27 & 0.94 \\
US & 0.28 & 0.21 & 0.27 & 0.26 & 0.18 & 0.22 \\
\hline Total & 0.58 & 0.20 & 0.37 & 0.29 & 0.24 & 0.50 \\
\hline
\end{tabular}

Notes: This table shows the standardised mean deviations (SMDs) of the indicator variables (first four columns) and the resulting finance-neutral output gap estimates (last two columns) with respect to the reference model with HP-filtered indicators. See the text for the exact definition of the SMD measures. In the reference model, the cycle indicators are HP-filtered with $\lambda=$ 400,000. The alternative pre-treatment methods are: de-trended indicators by second or third order polynomials; and the gap of indicator variables obtained from the semi-structural UCM.

Table 2: The impact of alternative pre-filtering methods on the resulting output gap estimates

\begin{tabular}{|c|c|c|c|c|}
\hline & $\begin{array}{c}\text { extended HP } \\
\text { (1) }\end{array}$ & $\begin{array}{c}\text { semi-struct. VAR } \\
\text { (2) }\end{array}$ & $\begin{array}{c}\text { extended HP } \\
\text { (3) }\end{array}$ & $\begin{array}{c}\text { semi-struct. VAR } \\
\text { (4) }\end{array}$ \\
\hline Reference model (ref.) & $\begin{array}{l}\text { HP-filtered } \\
\text { indicators }\end{array}$ & $\begin{array}{l}\text { HP-filtered } \\
\text { indicators }\end{array}$ & $\begin{array}{l}\text { semi-struct. } \\
\text { UCM }\end{array}$ & $\begin{array}{l}\text { semi-struct. } \\
\text { UCM }\end{array}$ \\
\hline adjusted R2 & 0.66 & 0.01 & 0.41 & 0.15 \\
\hline $\mathrm{Nb}$. of obs. & 4101 & 4020 & 4101 & 4020 \\
\hline$\hat{u}_{t}-\hat{u}_{t}^{\text {ref. }}$ & $\begin{array}{c}-0.24 * * * \\
(0.014)\end{array}$ & $\begin{array}{l}-0.11 * * \\
(0.044)\end{array}$ & $\begin{array}{c}-0.76 * * * \\
(0.027)\end{array}$ & $\begin{array}{c}-0.76 * * * \\
(0.042)\end{array}$ \\
\hline$\hat{c}_{t}-\hat{c}_{t}^{\mathrm{ref}}$ & $\begin{array}{c}0.46 * * * \\
(0.014)\end{array}$ & $\begin{array}{l}-0.06 * * \\
(0.028)\end{array}$ & $\begin{array}{c}0.07 * * * \\
(0.013)\end{array}$ & $\begin{array}{c}-0.27 * * * \\
(0.021)\end{array}$ \\
\hline$\hat{c} r_{t}-\hat{c r}{ }_{t}^{\text {ref. }}$ & $\begin{array}{l}0.01 * * * \\
(0.002)\end{array}$ & $\begin{array}{c}-0.04 * * * \\
(0.007)\end{array}$ & $\begin{array}{l}0.04 * * * \\
(0.003)\end{array}$ & $\begin{array}{l}0.02 * * * \\
(0.005)\end{array}$ \\
\hline$\hat{h p_{t}}-\hat{h p_{t}^{\text {ref. }}}$ & $\begin{array}{c}0.06 * * * \\
(0.002)\end{array}$ & $\begin{array}{l}0.04 * * * \\
(0.007)\end{array}$ & $\begin{array}{l}0.07 * * * \\
(0.003)\end{array}$ & $\begin{array}{c}0.07 * * * \\
(0.005)\end{array}$ \\
\hline
\end{tabular}

Notes: This table presents the results from a pooled ordinary least squares estimation in which the differences in output gaps are regressed on differences in the indicator measures. The reference model is the one with HP-filtered cycle indicators (the first two columns) or the semi-structural UCM (the last two columns). Other models considered: de-trended indicators by second or third order polynomials. 
A similar conclusion is reached when the output gap estimates of the semi-structural UCM are set as a reference. The same exercise as before is repeated in column 3 and 4 of Table 2, but the differences are calculated with respect to the semi-structural UCM. The alternative pre-treatment methods considered are: HP-filtered indicators with $\lambda=400,000$; and de-trended indicators by second or third order polynomials. These simple linear models lead to an adjusted R2 of 41 per cent for the extended HP and 15 per cent for the semi-structural VAR. That is, the closer the cycle indicators are to the results of the semi-structural UCM, the closer the estimated gaps with the extended HP model will be to the output gap estimates of the semi-structural UCM. Crucially, the differences and similarities of these two UCMs depend on the pre-treatment method applied to the auxiliary variables. This is much less true for the semi-structural VAR.

\subsection{Real time performance}

To assess the real-time performance of the models, we compute the average revision of the output gap as $\sum_{t=t_{0}}^{T} \frac{1}{T-t_{0}+1} \frac{\left|\hat{y}_{i t}^{\prime}-\hat{y}_{i t}^{t}\right|}{\sigma_{i}}$, with $\hat{y}_{i t}^{t}$ and $\hat{y}_{i t}^{t^{\prime}}$ being the output gaps of country $i$ at date $t$ for a given model estimated with data respectively up to date $t$ or $t^{\prime} \in\{t+1$ year, $t+3$ years $\}, \sigma_{i}$ the standard deviation of the baseline extended HP filter, $t_{0}$ the first date used for the exercise (2000 was chosen so that the models are stabilised for all countries) and $T$ is the last usable date (2015 for $t^{\prime}=t+1$ year or 2013 for $\left.t^{\prime}=t+3\right) .^{13}$

To meaningfully compare different models (with possibly very different output gap volatility), the revisions are normalised using the standard deviation of the most simple model, the extended HP filter in its baseline specification. This ensures that for example a 1 point revision in the output gap translates into the same standardised revision independently of the model or the set of variables included in the model. Furthermore, this normalisation neutralises the volatility of each country's cycle - FR's cycle is much less volatile than ES's, for instance - which allows comparisons between countries.

Figure 3 shows the standardised average errors (SAE) made at a 1-year horizon (dots at the beginning of the arrows) and at a 3-year horizon (tip of the arrows) for the baseline model ("baseline") and the model augmented with financial variables ("w/ fin. variables"). The colours of the arrows correspond to different models: the extended HP filter (blue, model A), the semi-structural UCM (green, model B) and the semi-structural VAR (orange, model C). A 45-degree dashed line is added to each plot. For comparison, the grey arrows indicate the SAE made at a 1-year horizon and at a 3 -year horizon by a simple univariate HP filter (obviously, this model only has a baseline version).

Although there is no overall best performing model, the extended HP filter generally performs relatively well in terms of revision. It is the model the least revised both at the 1-year and 3-year

\footnotetext{
${ }^{13}$ As we use only the latest available vintage of the data, this exercise is more accurately called pseudo real-time. A real-time exercise would only use data available at the moment of the estimation. So the part of the revisions coming from the revisions to the data itself is disregarded. Yet Orphanides and Norden (2002) shows that the "the revision of published data is not the primary source of revisions in measured output gaps; the bulk of the problem is due to the pervasive unreliability of end-of-sample estimates of the trend in output."
} 
horizon in half of the countries (FR, IT, JP and UK), independently of the presence or absence of financial variables. The extended HP filter augmented with financial variables is particularly stable compared to the other models with financial cycle indicators: it is consistently the least revised model at the 1-year horizon, and it is also the least revised after 3 years for 6 out of 8 countries.

The semi structural models are generally less stable than the reduced form model. When financial variables are added to the models, the semi-structural UCM usually outperforms the semi-structural VAR in terms of stability, while the baseline results are more mixed. With financial variables, the semi-structural VAR appears to be particularly unstable for JP, the UK, ES, and (at the 3-year horizon) for IT. For the rest, the semi-structural VAR features revisions in the range of the other models.

Figure 3: Output gap revisions 1 and 3 years ahead
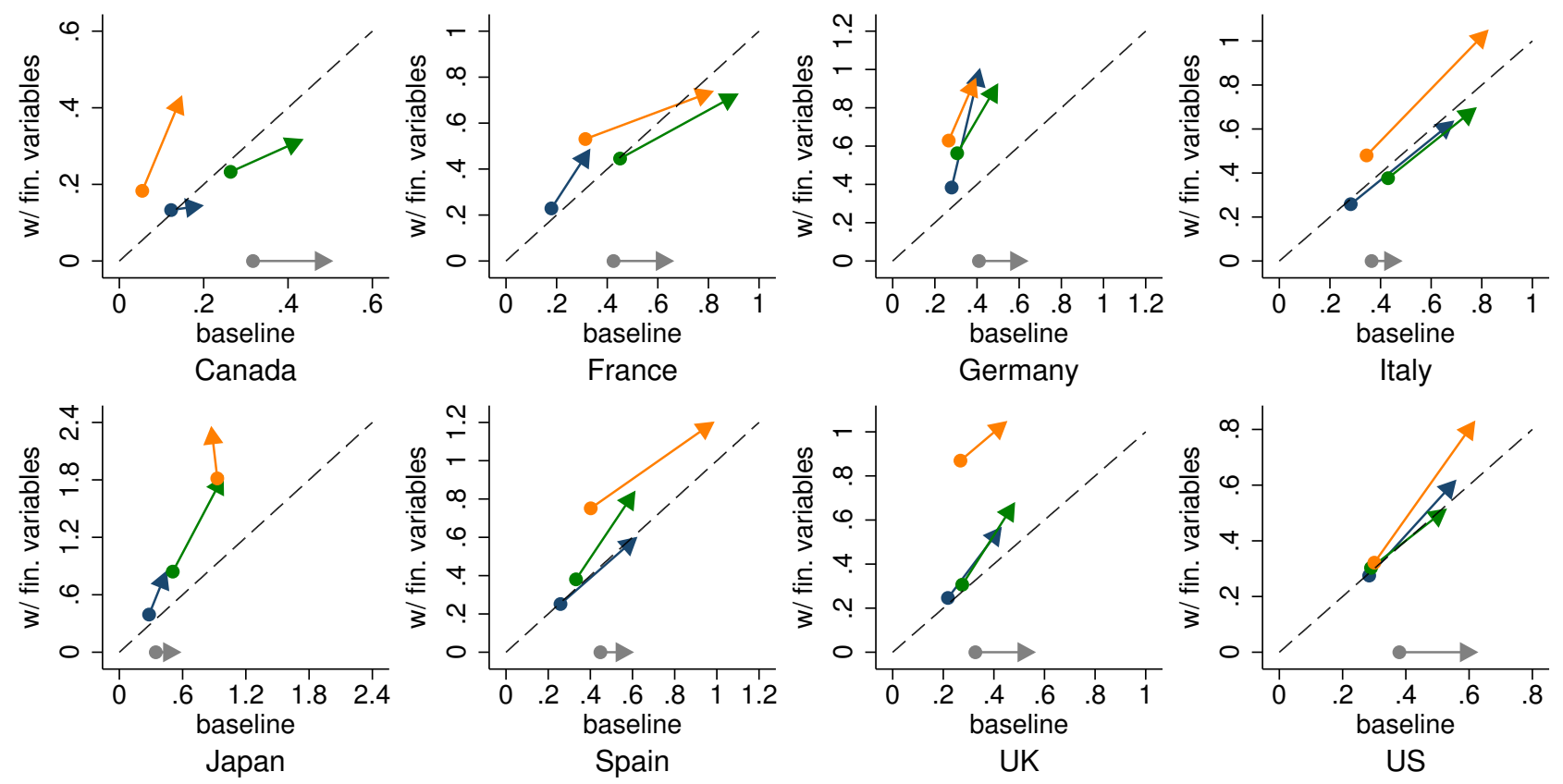

- extended HP $\bullet$ semi-struct. UCM $\bullet$ semi-struct. VAR $\bullet$ HP

Notes: This figure shows the standardised average errors (SAE) for each model and each country made at a 1-year horizon (dots at the beginning of the arrows) and at a 3-year horizon (tip of the arrows) for the baseline model ("baseline") and the model augmented with financial variables ("w/ fin. variables"). The colours of the arrows correspond to different models: the extended HP filter (blue, model A), the semi-structural UCM (green, model B) and the semi-structural VAR (orange, model C). A 45-degree dashed line is added to each plot. If, for example, the dot (tip of the arrow) is above the 45-degree dashed line, it means that the model augmented with financial variables is less stable in real-time 1 year (3 years) ahead than the baseline model; if the arrow is inclined more than 45 degrees from the horizontal, it means that the model augmented with financial variables is more revised between 1 and 3 years ahead than the baseline model. For comparison, the grey arrows indicate the SAE made at a 1-year horizon and at a 3-year horizon by a simple (univariate) HP filter (obviously, this model has only a baseline version). 
Apart from a few exceptions, financial information worsens the real-time stability of the models. Figure 3 shows that for almost all models and countries, the revision is higher at both the 1-year and the 3-year horizon with financial variables than in the baseline specification (the arrows are almost always above the 45 -degree lines). ${ }^{14}$

This seems to contradict some of the previous results, in particular the conclusion of Borio et al. (2017), Grintzalis et al. (2017) and Melolinna and Tóth (2019). The reason for the discrepancy of the results is twofold. First, in the first two papers the authors use the ex-post gaps for each model for normalisation, i.e. they compute a revision relative to the model and set of variables. In contrast, the revision measure presented in this paper is absolute, expressed as a percentage of the standard deviation of the baseline extended HP filter. Given that the output gaps are generally more volatile with financial variables than without, the relative revision would appear to be smaller with financial variables than without even if the absolute revisions are the same. This normalisation choice matters considerably: using the standard deviation of each model and set of variables, we also find on average smaller relative revisions with financial variables than without.

Second, Borio et al. (2017) and Grintzalis et al. (2017) do not assess the impact on real-time performance of the additional information from financial variables to business cycle variables, but instead compare an HP filter with a model with credit and house prices only - without unemployment or capacity utilisation to account for usual business cycles. Yet Borio et al. (2014a) also shows that (i) the HP filter involves huge revisions, (ii) using unemployment alone entails the smallest revisions in the output gap, and (iii) adding credit and house prices growth to unemployment generates larger revisions. These conclusions are perfectly in line with our results: Figure 3 reveals that the baseline extended HP filter is more stable than the traditional HP filter (grey arrow). The only exception is the extended HP filter for IT, which generates relatively high revisions at the 3-year horizon.

Figure 4 assesses the performance of the various models before and during the Great Recession for the four countries for which financial imbalances are identified ex-post (Figure 1 shows that these countries are FR, ES, the US, and the UK). For each of these countries, we plot the real-time estimates for the different models, with or without financial variables. Each line shows the output gap as estimated using data up to date $t \in[2007,2009,2011,2013,2015]$ and on the whole sample (red line).

Revisions are significant for all models and countries around the crisis, at times when new information is not in line with previous developments and thus shines a new light on the present and recent past. This is equally true for models on average less revised (extended HP) and more revised (semi-structural VAR), and for models with or without financial variables.

\footnotetext{
${ }^{14}$ There are only two exceptions: for FR, adding financial variables to the semi-structural models seems to improve the real-time stability of the models at the 3-year horizon; and for CA even though financial cycles do not seem to play a major role, the stability of the semi-structural UCM is improved at the 3-year horizon. For the other countries, financial information worsens the real-time stability of the models or only marginally improves it.
} 
Nevertheless, the fact that the models with financial variables do not carry small revisions during the crisis does not mean that they do not carry any useful information. A robust real-time performance is an advantage, but the ability to signal (possible) unsustainable economic developments in realtime - despite the relatively large subsequent revisions - is an equally important aspect to take into consideration. As the figures show, the inclusion of financial variables consistently leads to larger output gaps as estimated before the crisis (2007, or 2006 for the US): although adding financial variables does not lead to more precise output gap estimates before or during a crisis in terms of future revisions, on average it does provide a clearer real-time signal for booms and busts. The only exception is the UK, the country for which our estimation sample starting at 1985q1 is likely to be insufficient for identifying financial cycles and capturing their impact on GDP when only the precrisis period is taken into account. But even in this case, the models with financial variables adjust the subsequent output gap estimates more aggressively in response to new data for the crisis period.

Finally, the figures below suggest that the semi-structural VAR model is, on average, more successful in capturing the pre-crisis overheating: for the last year before the crisis, it either indicates the largest output gap (baseline estimate for FR and US; and finance-neutral estimate for FR and ES) or similar imbalances to the other models.

Figure 4: Real-time estimates
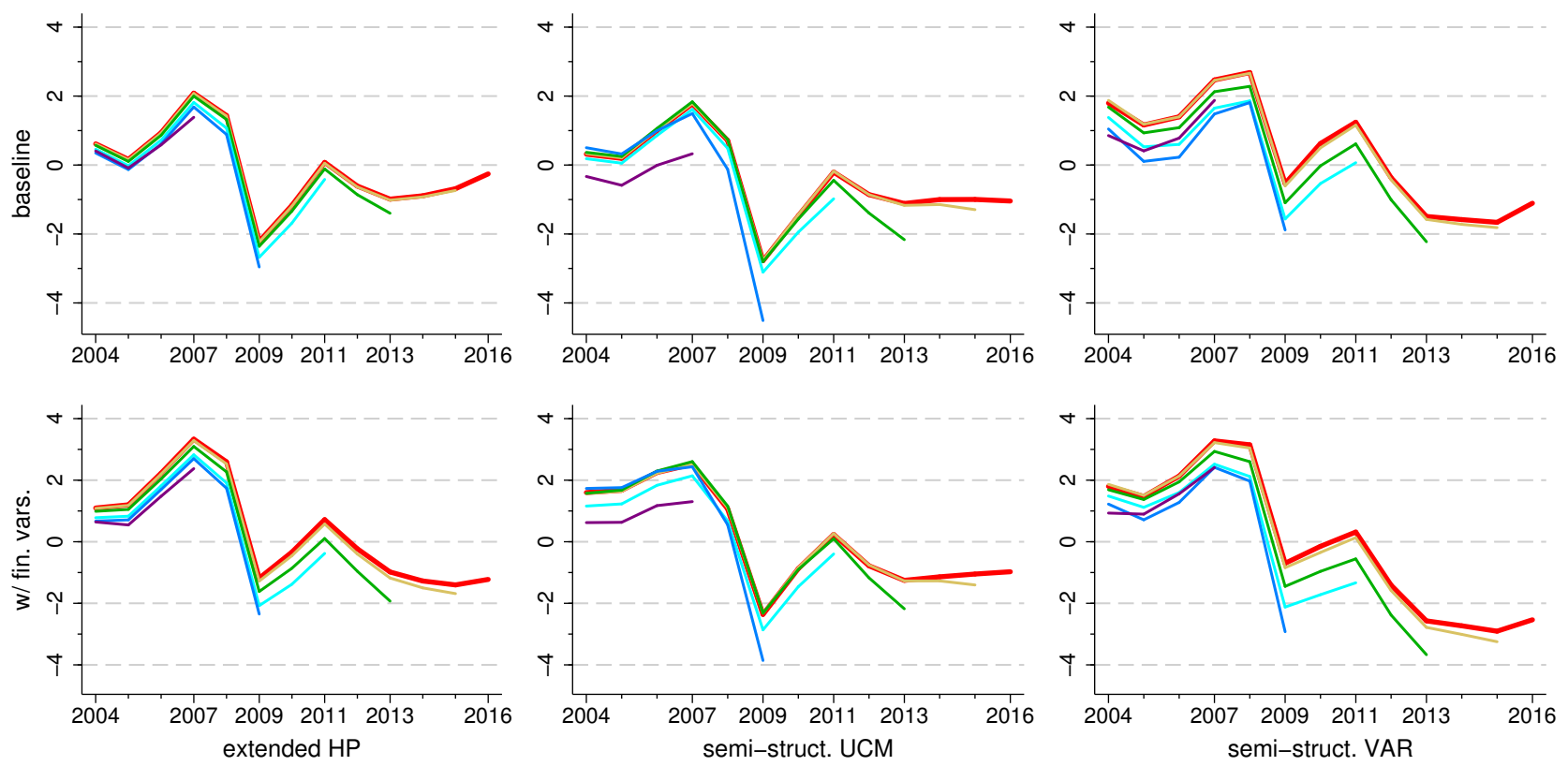

(a) France, 2007-2016 

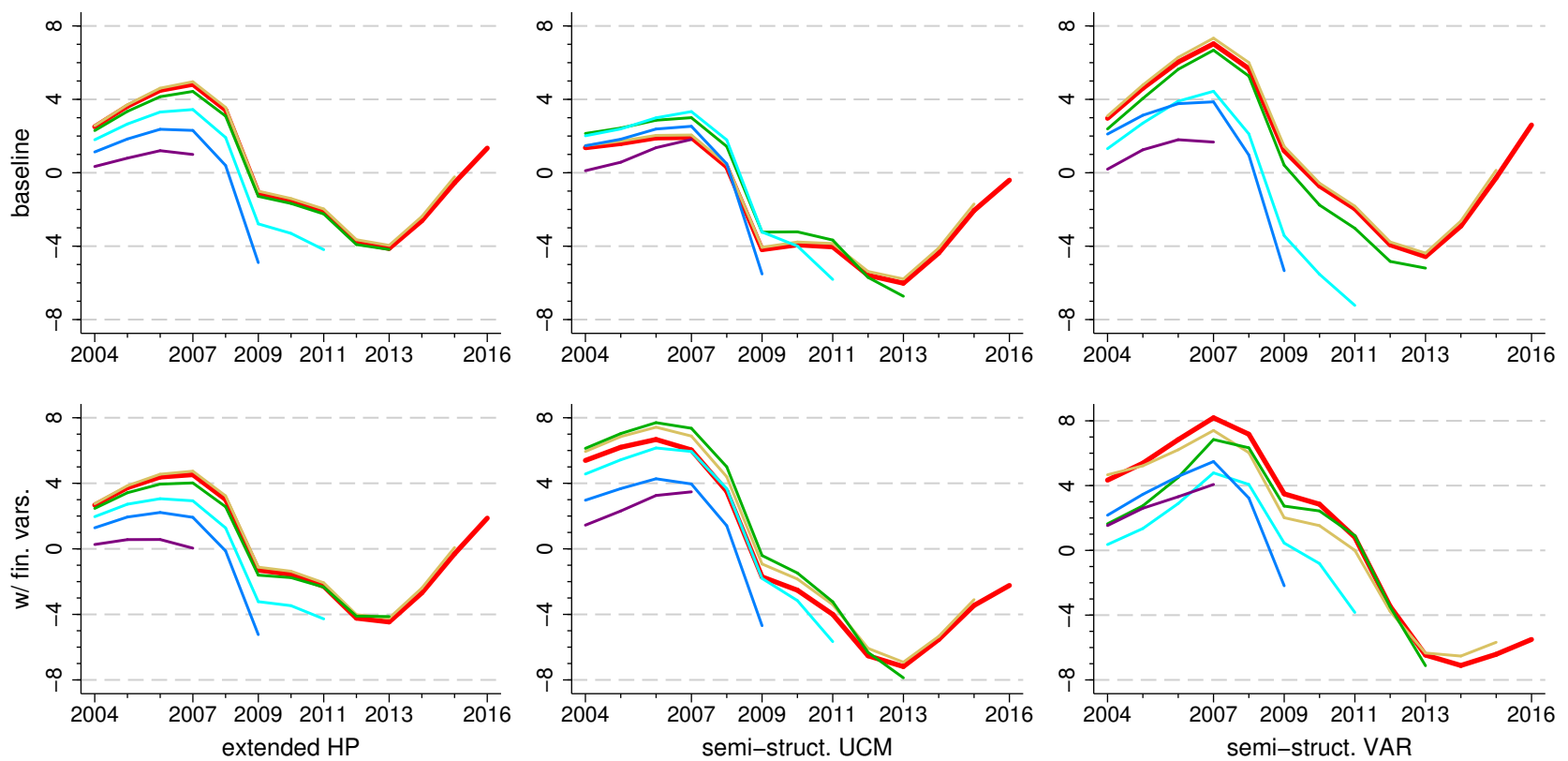

(b) Spain, 2007-2016
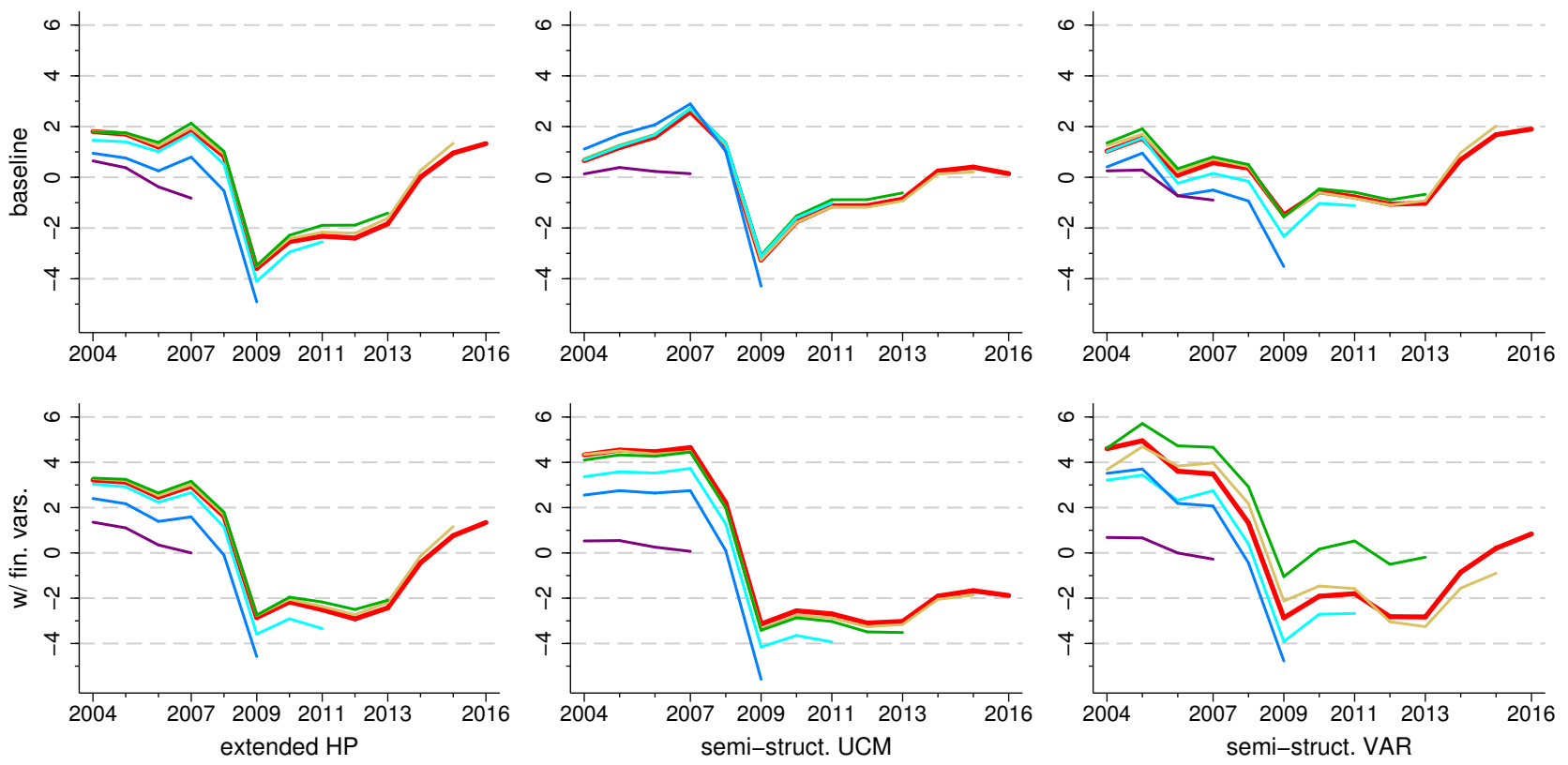

(c) UK, 2007-2016 

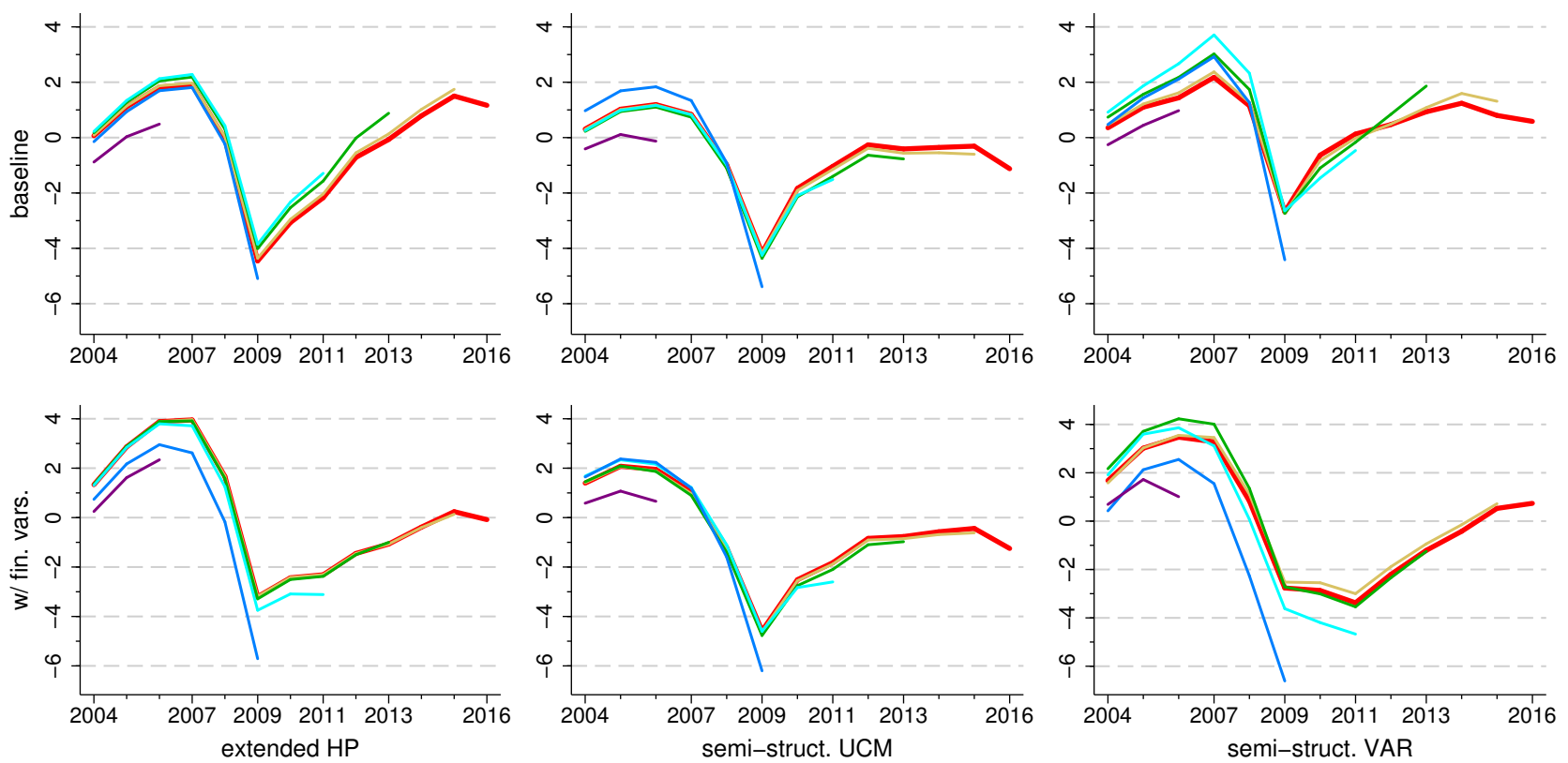

(d) US, 2006-2016

Notes: Figures 4(a) to 4(d) show the real-time estimates of the extended HP filter (left), the semi-structural UCM (middle) and the semi-structural VAR (right). The graphs in the top row correspond to the baseline model and those in the bottom row to the models augmented with credit and house prices. Each line shows the output gap as estimated using data up to date $t \in[2007,2009,2011,2013,2015]$ and on the whole sample (red line). For the US, since the crisis started earlier than in the other countries, the first estimate corresponds to 2006 instead of 2007 (purple line).

\subsection{Receiver operating characteristic analysis}

The accuracy of the estimated output gaps and the models' early warning capabilities in real-time are assessed using receiver operating characteristic (ROC) analysis. The performance of each model (extended HP, semi-structural UCM and semi-structural VAR) and model variant (baseline and extended with financial variables) is assessed based on how accurately the estimated output gap can predict recessions.

The core of the analysis is a probit equation that relates the probability of country $i$ being in recession $\left(R_{i t}=1\right)$ to the estimated output gap $h$ quarters earlier $\left(\hat{y}_{i, t-h}^{m}\right)$ obtained from the model $m$. As in Section 4.5, the output gaps are normalised using the standard deviation of the baseline extended HP filter. Recession is defined as two consecutive quarters of negative seasonally adjusted GDP growth. We exclude "mild recessions" from the analysis, defined as a recession which lasts less than a year and results in a drop in GDP of less than 1 per cent. 10 such "mild" recession periods are identified. In total, we identify 33 recession periods which last between 2 and 11 quarters. The highest number of recession periods is in DE, while FR and the UK each experienced only 2 recession periods in our sample. The full list of recession periods are provided in Appendix D.

By definition, $R_{i t}$ follows an autoregressive process. Therefore, the probit model also includes the lagged values of the state of the economy $\left(\sum_{l=1}^{L} \rho_{l} R_{i, t-l}\right)$. Due to the low number of recession 
periods in some of the countries, no reliable and robust estimate can be obtained separately for each country. Hence, we estimate the following dynamic probit model for the panel of the eight countries:

$$
\operatorname{Pr}\left(R_{i t}=1 \mid R_{i, t-1}, \ldots, R_{i, t-l}, \hat{y}_{i, t-h}\right)=\Phi\left(\sum_{l=1}^{L} \rho_{l} R_{i, t-l}+\delta \hat{y}_{i, t-h}^{m}\right)
$$

where $\Phi$ is is the cumulative distribution function of the standard normal distribution. ${ }^{15}$

Using the estimated probit equation, we first predict the probability of being in recession conditional on $R_{i, t-l}=0, l \in\{1, \ldots, L\}$. The predicted conditional probabilities are then used to estimate the ROC curve. For a number of different candidate probability threshold values between 0 and 1 , the ROC curve plots the fraction of "true positive" events (recessions that are correctly identified by the model for a given threshold, a.k.a. sensitivity) against the fraction of "false positive" events (predicted recessions that did not occur, a.k.a. 1 -specificity). The Area Under the ROC Curve (AUC) is the integral of the ROC curve, which provides a comparable aggregate metric that quantifies the overall accuracy of the prediction by taking into account both true and false signals. See Pepe (2003) for a general review of the ROC methodology.

The main difficulty of the analysis is that the performance of the estimated output gap as a leading indicator for recession cannot be clearly separated from the forecasting performance of the probit model. In particular, the optimal lag structure of eq. 14 may vary by country and by model. All models and countries considered, the distance between the date of entry into recession and the closest peak in the estimated output gap ranges between -1 and 29 quarters, with an average of 8.3 and a standard deviation of 6 quarters (see Appendix E for the definition of our distance measure and the histogram of the distances).

Instead of relying on a single probit specification, we therefore analyse a large number of alternative probit models with different lag selection criterion. First, for each output gap estimate $\hat{y}_{i t}^{m}$, the optimal lag $h$ and the order of the autoregressive process $L$ are selected based on the criterion that maximises the AUC. ${ }^{16}$ Second, we re-estimate the probit equations and the corresponding AUCs using the same lag structure for all models. For example, if the optimal $h$ in the previous exercise turn out to be 5,11 and 12 for the various models, we repeat the same exercise and compare the AUCs obtained from the same probit specification for each $\hat{y}_{i t}^{m}$ with $h$ equal to 5, 11, and then 12 . Third, we estimate a distributed lag model by replacing $\delta \hat{y}_{i, t-h}^{m}$ at the right-hand side of eq. 14 by $\sum_{j=h}^{H} \delta_{j} \hat{y}_{i t-j}^{m}$. The optimal minimum $(h)$ and maximum $(H)$ lags are the ones that maximise the resulting AUC. Finally, instead of maximising the AUC, we used the Bayesian Information Criterion (BIC) or the Akaike Information Criterion (AIC) to select the optimal $h$ and $L$.

The first row (a) of Table 3 presents the average AUCs obtained from these probit model specifications. The corresponding standard errors are calculated as $\left(C V C^{\prime}\right)^{1 / 2}$, where $C$ is a $1 \times k$ row

\footnotetext{
${ }^{15}$ We estimate eq. 14 as a simple pooled panel probit model. A dynamic random effects probit with unobserved heterogeneity, estimated as proposed by Wooldridge (2005), yields very similar results.

${ }^{16} h$ is allowed to vary between 1 and 16 quarters, and $L$ between 1 and 4 quarters. We used these boundary conditions for all other selection criteria as well. The optimal $h$ and $L$ are always lower than the upper bounds.
} 
vector with elements $1 / k, k$ is the number of estimated probit specifications for a given model $m$, and $V$ is the variance-covariance matrix of the estimated AUCs calculated as described in DeLong et al. (1988). To test the differences between the average AUCs, we use a $1 \times 2 k$ contrast matrix $C=(1, \ldots, 1,-1, \ldots,-1)$. The first $k$ elements with a value of 1 correspond to the vector of AUCs of a given model $m$, while the remaining $k$ elements with a value of -1 correspond to the AUCs of another model to which the first one is confronted. The method for performing a test of significance for a given contrast matrix is described in detail in DeLong et al. (1988). Intuitively, the contrast matrix previously defined tests whether the sum of the AUCs obtained for the model $m$ minus the sum of the AUCs obtained for another model is significantly different from zero. In row (b) of Table 3, we compare, for each model, the baseline specification with the model with financial variables. In rows (c) and (d), the AUCs obtained for the extended HP, the semi-structural UCM and the semi-structural VAR are compared, separately for the baseline model and the model with financial variables.

The second block of the table (rows e-h) presents the results for the real-time output gap estimates (see Section 4.5). Using the probit model estimated on the full sample, we first predict the conditional probability of being in recession with the output gap estimated on the sample up to 2000q4. For each subsequent year $t \in\{2001, \ldots, 2016\}$, we predict the same probability using the output gap obtained from the model estimated until $t$. We then compute the AUCs using the resulting real-time predictions.

Finally, the bottom panel (B) of Table 3 repeats the same exercise as before on the restricted sample of four countries with visible impact of financial cycles before the Great Recession: FR, ES, the UK and the US (see Section 4.5).

Overall, results reveal that, for each model, the average AUCs obtained from the models with financial variables are significantly higher than the corresponding AUCs of the baseline models. The only exception is the real-time forecast using the extended HP for the panel of eight countries (in row e, and the corresponding test in row f): although the model with financial variables yields higher AUC than the baseline model, the difference is not statistically significant. The difference between the AUCs is systematically higher for the restricted sample. The largest difference is obtained for the real-time forecast using the the semi-structural VAR on the restricted sample (see rows $\mathrm{m}$ and $\mathrm{n}$ ).

We arrive to the same conclusion when each of the probit specification and estimation sample are separately assessed. In the vast majority of the cases, adding financial variables improves the forecasting performance of the models. Out of the 96 model comparisons (16 probit specifications $\times 3$ models, in-sample and real-time forecasting performance), the models with financial variables yield higher AUCs in 93 cases, out of which 68 are significant at the 5\% level and an additional 7 are significant at the $10 \%$ level. There are only 3 cases in which the baseline AUCs are higher than those with the financial variables, and the difference is significant in 1 case only. On the restricted sample, the superiority of the model with financial variables is even more obvious: out of the 54 comparison tests performed, the AUCs with financial variables are significantly higher at the 5\% level than the baseline model in 52 cases; it is higher at the $10 \%$ significance level in 1 case; and it is higher, but the difference is not statistically significant in 1 case. Together with the tests performed on the average AUCs presented in Table 3, these results provide robust evidence that financial variables enhance the models' forecasting performance. 
Table 3: Receiver operating characteristic (ROC) analysis

\begin{tabular}{|c|c|c|c|c|c|c|}
\hline & \multicolumn{2}{|c|}{ extended HP } & \multicolumn{2}{|c|}{ semi-struct. UCM } & \multicolumn{2}{|c|}{ semi-struct. VAR } \\
\hline & baseline & w/ fin. vars. & baseline & w/ fin. vars. & baseline & w/ fin. vars. \\
\hline & \multicolumn{6}{|c|}{ (A) Full sample } \\
\hline (a) AUC (in-sample) & $\begin{array}{c}0.63 \\
(0.019)\end{array}$ & $\begin{array}{c}0.65 \\
(0.020)\end{array}$ & $\begin{array}{c}0.58 \\
(0.022)\end{array}$ & $\begin{array}{c}0.69 \\
(0.024)\end{array}$ & $\begin{array}{c}0.69 \\
(0.018)\end{array}$ & $\begin{array}{c}0.73 \\
(0.018)\end{array}$ \\
\hline $\begin{array}{l}\text { (b) diff. w.r.t. } \\
\text { baseline }\end{array}$ & & $\begin{array}{c}0.02 * * \\
(\mathrm{p}=0.037)\end{array}$ & & $\begin{array}{c}0.11 * * * \\
(\mathrm{p}<0.001)\end{array}$ & & $\begin{array}{c}0.03 * * \\
(\mathrm{p}=0.037)\end{array}$ \\
\hline $\begin{array}{l}\text { (c) diff. w.r.t. } \\
\text { extended HP }\end{array}$ & & & $\begin{array}{c}-0.05^{* * * *} \\
(\mathrm{p}<0.001)\end{array}$ & $\begin{array}{c}0.04 * * \\
(\mathrm{p}=0.037)\end{array}$ & $\begin{array}{c}0.07 * * * \\
(\mathrm{p}<0.001)\end{array}$ & $\begin{array}{c}0.08^{* * * *} \\
(\mathrm{p}<0.001)\end{array}$ \\
\hline $\begin{array}{l}\text { (d) diff. w.r.t. semi- } \\
\text { struct. UCM }\end{array}$ & & & & & $\begin{array}{c}0.11 * * * \\
(\mathrm{p}<0.001)\end{array}$ & $\begin{array}{c}0.04 * \\
(p=0.075)\end{array}$ \\
\hline (e) AUC (real-time) & $\begin{array}{c}0.58 \\
(0.020)\end{array}$ & $\begin{array}{c}0.60 \\
(0.023)\end{array}$ & $\begin{array}{c}0.61 \\
(0.023)\end{array}$ & $\begin{array}{c}0.69 \\
(0.025)\end{array}$ & $\begin{array}{c}0.60 \\
(0.021)\end{array}$ & $\begin{array}{c}0.67 \\
(0.022)\end{array}$ \\
\hline $\begin{array}{l}\text { (f) diff. w.r.t. } \\
\text { baseline }\end{array}$ & & $\begin{array}{c}0.02 \\
(\mathrm{p}=0.253)\end{array}$ & & $\begin{array}{c}0.08 * * * \\
(\mathrm{p}<0.001)\end{array}$ & & $\begin{array}{c}0.07 * * * \\
(\mathrm{p}=0.004)\end{array}$ \\
\hline $\begin{array}{l}\text { (g) diff. w.r.t. } \\
\text { extended HP }\end{array}$ & & & $\begin{array}{c}0.03 * * \\
(p=0.049)\end{array}$ & $\begin{array}{c}0.09 * * * \\
(\mathrm{p}<0.001)\end{array}$ & $\begin{array}{c}0.02 \\
(p=0.379)\end{array}$ & $\begin{array}{c}0.07 * * * \\
(\mathrm{p}=0.001)\end{array}$ \\
\hline \multirow[t]{2}{*}{$\begin{array}{l}\text { (h) diff. w.r.t. } \\
\text { semi-struct. UCM }\end{array}$} & & & & & $\begin{array}{c}-0.01 \\
(\mathrm{p}=0.442)\end{array}$ & $\begin{array}{c}-0.03 \\
(p=0.145)\end{array}$ \\
\hline & \multicolumn{6}{|c|}{ (B) Restricted sample (four countries) } \\
\hline (i) AUC (in-sample) & $\begin{array}{c}0.68 \\
(0.031)\end{array}$ & $\begin{array}{c}0.74 \\
(0.034)\end{array}$ & $\begin{array}{c}0.66 \\
(0.042)\end{array}$ & $\begin{array}{c}0.78 \\
(0.031)\end{array}$ & $\begin{array}{c}0.72 \\
(0.030)\end{array}$ & $\begin{array}{c}0.85 \\
(0.018)\end{array}$ \\
\hline $\begin{array}{l}\text { (j) diff. w.r.t. } \\
\text { baseline }\end{array}$ & & $\begin{array}{c}0.06^{* * * *} \\
(\mathrm{p}<0.001)\end{array}$ & & $\begin{array}{c}0.12 * * * \\
(\mathrm{p}<0.001)\end{array}$ & & $\begin{array}{c}0.13^{* * *} \\
(\mathrm{p}<0.001)\end{array}$ \\
\hline $\begin{array}{l}\text { (k) diff. w.r.t. } \\
\text { extended HP }\end{array}$ & & & $\begin{array}{c}-0.03 \\
(p=0.139)\end{array}$ & $\begin{array}{c}0.04 * * \\
(\mathrm{p}=0.024)\end{array}$ & $\begin{array}{c}0.04 \\
(p=0.305)\end{array}$ & $\begin{array}{c}0.11^{* * * *} \\
(\mathrm{p}=0.001)\end{array}$ \\
\hline $\begin{array}{l}\text { (l) diff. w.r.t. semi- } \\
\text { struct. UCM }\end{array}$ & & & & & $\begin{array}{c}0.06 \\
(\mathrm{p}=0.185)\end{array}$ & $\begin{array}{c}0.07 * * \\
(p=0.018)\end{array}$ \\
\hline (m) AUC (real-time) & $\begin{array}{c}0.64 \\
(0.034)\end{array}$ & $\begin{array}{c}0.68 \\
(0.037)\end{array}$ & $\begin{array}{c}0.70 \\
(0.039)\end{array}$ & $\begin{array}{c}0.83 \\
(0.023)\end{array}$ & $\begin{array}{c}0.65 \\
(0.035)\end{array}$ & $\begin{array}{c}0.83 \\
(0.018)\end{array}$ \\
\hline $\begin{array}{l}\text { (n) diff. w.r.t. } \\
\text { baseline }\end{array}$ & & $\begin{array}{c}0.05^{* * * *} \\
(\mathrm{p}<0.001)\end{array}$ & & $\begin{array}{c}0.13^{* * * *} \\
(\mathrm{p}<0.001)\end{array}$ & & $\begin{array}{c}0.18^{* * * *} \\
(\mathrm{p}<0.001)\end{array}$ \\
\hline $\begin{array}{l}\text { (o) diff. w.r.t. } \\
\text { extended HP }\end{array}$ & & & $\begin{array}{c}0.06^{* * * *} \\
(\mathrm{p}<0.001)\end{array}$ & $\begin{array}{c}0.15^{* * * *} \\
(\mathrm{p}<0.001)\end{array}$ & $\begin{array}{c}0.02 \\
(p=0.502)\end{array}$ & $\begin{array}{c}0.15^{* * * *} \\
(\mathrm{p}<0.001)\end{array}$ \\
\hline $\begin{array}{l}\text { (p) diff. w.r.t. } \\
\text { semi-struct. UCM }\end{array}$ & & & & & $\begin{array}{c}-0.05^{*} \\
(\mathrm{p}=0.073)\end{array}$ & $\begin{array}{c}0.00 \\
(p=0.969)\end{array}$ \\
\hline
\end{tabular}

Notes: Row (a) presents the average AUCs obtained from a set of probit model specifications. Row (b) compares, for each model, the baseline specification with the model with financial variables. In rows (c) and (d), the AUCs obtained for the various models are compared. The second block of the table (rows e-h) presents the results for the real-time output gap estimates. The bottom panel $(B)$ shows the same results for a restricted sample of four countries: FR, ES, the UK and the US. See the text for more details. 
In terms of model comparison, results are more mixed. When financial variables are added to the models, both semi-structural models seem to significantly outperform the extended HP filter (see the tests in rows $\mathrm{c}, \mathrm{g}, \mathrm{k}$ and $\mathrm{o}$ ). Comparing the two semi-structural models with financial variables, the VAR seems to have an edge over the UCM in terms of in-sample forecasting accuracy (see rows d and 1 ), but there is no significant difference in their forecasting performance in real-time (rows $h$ and p). No clear message emerges for the baseline specifications.

These results are consistent with the conclusions drawn from the comparison of the results of each probit specification and estimation sample. In about 28 per cent of the cases (9 out of 32), the differences between the AUCs for the three models with financial variables are not statistically significant. ${ }^{17}$ The semi-structural UCM has either the highest or not significantly different from the highest AUC in 21 out of the remaining 23 cases. The same number for the semi-structural UCM is 15 , while there is only one case in which the extended HP shares the first place with the semi-structural VAR. To put it differently, when financial variables are included in the models, the semi-structural VAR significantly falls behind the best performing model in 2 cases only. The semi-structural UCM is the close second with 8 such cases, while the extended HP filter lags behind the best performing model in 22 cases.

At last, we also repeat the same exercise using an alternative, more flexible dependent variable in the probit equation 14. Instead of predicting the probability of being in recession exactly $h$ periods ahead, $R_{i t}$ is defined as being in recession during a one-year interval between $t$ and $t+3$. The resulting AUCs are systematically higher with this more flexible recession definition. Overall, all our previous conclusions hold true even when the more flexible probit is considered.

\section{Discussion and conclusion}

This paper estimates the sustainable growth and the finance-neutral output gap for eight advanced economies: CA, FR, DE, IT, JP, ES, the UK and the US. We test the implications of incorporating financial cycle indicators into various signal extraction models. As a first step, we estimate three "baseline" models: (A) a reduced form "extended HP filter", advanced by Borio et al. (2017), in which business and financial cycle indicators are directly incorporated into the state-space representation of the HP filter as deterministic covariates; (B) a simple semi-structural UCM featuring a Phillips curve, an Okun's law and a stochastic process relating output gap to capacity utilisation; and (C) a new approach, a multivariate semi-structural VAR with long-run restrictions à la Blanchard and Quah (1989) in which only one of the several structural shocks (the supply shock) is recovered. Usual business cycles are captured in these models by the unemployment rate, the capacity utilisation rate and (in the semi-structural model) CPI inflation. As a second step, the implications of adding data on credit and on house prices to capture financial cycles are tested.

The three models have different properties along several important dimensions. The comparison of the two UCMs (models A and B) assesses the practical advantages and the potential pitfalls of

\footnotetext{
${ }^{17}$ This includes the cases in which no clear winner can be identified, e.g. when $A>B, A=C$ and $\left.B=C\right)$.
} 
treating the cycle indicator variables as deterministic (as in model A) compared to modelling them as stochastic processes (as in model B). On the one hand, the reduced form extended HP filter is particularly appealing for its simplicity and real-time stability. Indeed, there are only a limited number of parameters to estimate, the identification of the model is quite straightforward and, as a consequence, the model exhibits relatively stable output gap estimates in terms of real-time revisions. With financial variables, this model is particularly stable compared to the other models: it is the least revised model at the 1-year horizon for all countries considered, and it is also the least revised after 3 years for 6 out of 8 countries.

On the other hand, this approach requires accurate and readily available cycle indicators to achieve unbiased output gap estimates. Since "pure" business or financial cycle indicators unaffected by structural changes are in practice almost never available, some form of pre-transformation should be applied to the auxiliary variables before feeding them into the model. A variety of alternative stationary-inducing transformations can be employed. For example, if the time series is supposed to be trend stationary, de-trending the data by regressing out a - linear or higher order, depending on properties of the time series - time trend is a valid approach. A different procedure involves detrending the data by filtering out very low frequency signals, but still allowing the trend to slowly evolve following a stochastic process. In principle, any pre-transformation is valid if it leads to stationary time series. The difficulty is to select the best approach that results in the most accurate cycle indicator. ${ }^{18}$

Results suggest that the choice of the pre-treatment method is very important. If the pre-transformed indicator does not accurately capture the cyclical pattern of the variable at the relevant frequency range, the variable plugged into the model can either receive a positive weight and transmit the bias to the estimated output gap, or with a (close to) zero coefficient it cannot impact the estimated output gap. For example, our results indicate that a relatively standard pre-treatment of the business and financial cycle indicators using a HP filter with smoothing parameter $(\lambda)$ of 400,000 leads to a likely under-estimation of the importance of credit cycles in the UK. In fact, this approach can be viewed as a two step procedure, in which possible structural shocks to the indicator variables are first removed before their impact on the cyclical pattern of GDP is assessed. By re-estimating the model for all countries using various alternative trend removal techniques, we show that close to half of the differences in the output gap estimates compared to the semi-structural UCM can be explained by the differences between the pre-treated cycle indicators and the cyclical parts of the same indicator estimated using the semi-structural UCM.

Since the semi-structural UCM allows for stochastic shocks to the trend of business cycle indicators and financial variables, the model can be viewed as the simultaneous estimation of these two steps. However, this flexibility is not without a price. Although the method does not require pretransforming the business and financial cycle indicators, it does require introducing potentially strong prior judgements by choosing the structure of the model and by defining Bayesian prior distributions

\footnotetext{
${ }^{18}$ In a broader sense, the seasonal adjustment applied to original series is also a form of pre-transformation. While the seasonal adjustment filters out signals at the yearly frequency, de-trending the series (either by regressing out a deterministic trend or by applying a filter) removes very low frequency signals.
} 
on the parameters. To illustrate the benefits and potential shortcomings of this approach, this paper presents a simple yet widely used UCM with very light structure and standard Bayesian prior beliefs about the parameters. While the baseline output gap estimates are generally close to those obtained using the extended HP filter, there are several examples showing that the two UCMs use the additional information provided by the financial variables differently. For example, the cases of JP and - to a lesser extent - the US illustrate how different approaches trigger different results and give a warning that relying on a more flexible approach may also lead to misleading conclusions. More in line with the Japanese "Lost Decade" paradigm, the extended HP filter reveals a significantly higher and more prolonged impact of the Japanese financial bubble of the 1990s than the semi-structural UCM. Similarly, the reduced form model seems to better able to signal the "overheating" of the US economy before the global financial crisis than the semi-structural UCM.

The proposed semi-structural VAR addresses the difficulty of estimating the unobserved output gap from a different angle. Similarly to the bivariate Blanchard and Quah (1989) model, the beauty of this approach is that the identifying assumption perfectly matches with the definition of potential growth: only the (supply) shocks to the trend have permanent effects on GDP. In contrast to the original model, we exploit a wider set of information by using several (both regular business and financial) cycle indicators without imposing further restrictions. Since the model uses different identifying assumptions to recover the output gap, it can provide very informative insights in addition to the other UCM-based models - especially so since the two UCMs share the same basic structure. In the same way, it is also an ideal candidate for external validation of the UCMs' results. For example, the model reinforces the findings from the extended HP filter for JP and the US, while it rather gives credit to the semi-structural UCM in the case of the UK. As with the extended HP filter, one drawback of the semi-structural VAR is that the model is sensitive to the pre-treatment method applied to the auxiliary variables. However, compared to the reduced form UCM approach, the change in the resulting output gap estimates is much less predictable.

Both in terms of model used or the sets of variables incorporated in the models, our results highlight a possible trade-off between accurately disentangling short-term and long-term (sustainable) economic dynamics and the real-time stability of the output gap estimates. The deterioration of the real-time stability of the model with financial variables (compared to the model which already includes relevant business cycle indicators, such as unemployment and capacity utilisation) is a common feature of all approaches. The increased (absolute) revisions is typical both in the short-run and the longer-run, sometimes even for countries without clear financial cycles identified ex-post (most importantly for DE).

Although the stability of a model is an important aspect - since a model substantially revised when new data becomes available is of limited use for policy analysis -, relatively large revisions do not necessarily preclude the usefulness of the model. ${ }^{19}$ On the contrary: the models with financial variables included generally prove to be more successful in identifying unsustainable economic developments both ex-post and in real-time. By assessing the three models' forecasting perform-

\footnotetext{
${ }^{19}$ To give an extreme example, an unrealistic rigid model such as $\hat{y}_{t}=\pi_{t}-2$ is admittedly never revised, yet its poor accuracy makes it irrelevant.
} 
ance, the paper shows that including financial variables significantly improves the models' accuracy in predicting recessions. This is also true when real-time output gap estimates are used, in particular for the countries in which large pre-crisis imbalances are identified ex-post. For these countries, the models with financial variables consistently indicate larger pre-crisis (positive) output gap already before the outbreak of the crisis. To put it into policy perspective, credit and house prices in ES, for example, would have signalled a much larger boom before the 2008-09 crisis and could have helped the authorities to mitigate its impact.

In a similar vein, the trade-off between accuracy and real-time stability is also apparent when the various models are compared. While the semi structural models are generally less stable than the reduced form model, especially when financial variables are added to the models, they also seem to better capture the increase in macroeconomic and financial imbalances and to more accurately predict future recessions. Our proposed semi-structural VAR augmented with financial variables performs particularly well in terms of predicting power: it features the best in-sample forecasting performance of recession probabilities among all three models, and it has similar real-time prediction capabilities to the semi-structural UCM and clearly superior to the extended HP filter.

This brings us to the following more general conclusions. First, financial information should be taken into account when assessing the cyclical position of the economy. For most countries, there is already enough data and variability to estimate the interaction between financial cycles and GDP. Obviously, there is no guarantee that the models augmented with financial variables would accurately capture the build-up of imbalances coming from other sources. Moreover, even if the source is identified, it may not be possible to empirically assess its impact on GDP if the sample does not cover a sufficient number of cycles for this source. Nevertheless, the real-time results for the UK suggest that it is still beneficial to incorporate relevant information into the model after the burst of the bubble: the model may be quicker to adjust the subsequent output gap estimates as new data points become available.

Second, given the large uncertainty surrounding output gap estimates, as also illustrated by our results, relying on a single model (or a few closely related models that can be seen as model variants) is hardly enough to draw robust conclusions. In this regard, the proposed semi-structural VAR is an ideal complement of the more widely used UCM approaches. This paper does not propose a statistical method for weighting the different results. Instead, in order to avoid policy mistakes caused by, for example, false and short-lived signals of the more flexible approaches or, inversely, by failing to consider relevant information hidden (smoothed out) by the more stable models, it is sensible to monitor the results obtained from several methods.

Obviously, this paper does not cover all possible methods, not even within the UCM-based statistical filtering family. The comparison of the two UCMs presented in the paper illustrate one particularly relevant aspect of the methods, namely the implications of treating the (financial) cycle indicator variables as deterministic compared to modelling them as stochastic processes. Moreover, results from an alternative reduced form approach (model A', the "dynamic multivariate filter", presented in Appendix B) suggest that the exact formulation of the reduced form model is of limited practical relevance. Yet, the possibilities of adjusting the semi-structural UCM by imposing more structure 
on it are endless. Furthermore, by imposing the full general equilibrium structure of the model, we arrive at a second class of methods: the structural approaches (see e.g. the classification of Mishkin (2007)). In this approach, potential output is the "frictionless" part of GDP. Finally, according to the classification of Mishkin (2007), a separate class of methods is dedicated to the "production function" approach. However, from the methodological point of view this approach is not a trend-cycle decomposition technique per se: the input factors need to be decomposed - individually or simultaneously before recovering the potential growth and the output gap. These trend-cycle decompositions are usually carried out using simple univariate or small multivariate UCMs, but a semi-structural model with an additional restriction given by the production function relating the different (trend) input factors to (trend) GDP can, in principle, also be considered. Whether or not these additional restrictions are helpful to recover the finance-neutral output gap is ultimately an empirical question. We leave this for future research. 


\section{References}

Alberola-Ila, E., Gondo, R., Lombardi, M. J., and Urbina, D. (2016). Output gaps and policy stabilisation in Latin America: the effect of commodity and capital flow cycles. Technical Report 568, Bank for International Settlements.

Amador-Torres, J. S., Gomez-Gonzalez, J. E., Ojeda-Joya, J. N., Jaulin-Mendez, O. F., and TenjoGalarza, F. (2016). Mind the gap: Computing finance-neutral output gaps in Latin-American economies. Economic Systems, 40(3):444-452.

Amisano, G. and Giannini, C. (1997). Topics in Structural VAR Econometrics. Springer Berlin Heidelberg, Berlin, Heidelberg.

Anderton, R., Aranki, T., Dieppe, A., Elding, C., Haroutunian, S., Jacquinot, P., Jarvis, V., Labhard, V., Rusinova, D., and Szörfi, B. (2014). Potential output from a euro area perspective. Occasional Paper Series 156, European Central Bank.

Andrle, M. (2013). What Is in Your Output Gap? Unified Framework \& Decomposition into Observables. IMF Working Paper 13/105, International Monetary Fund.

Anundsen, A. K., Gerdrup, K., Hansen, F., and Kragh-Sørensen, K. (2016). Bubbles and Crises: The Role of House Prices and Credit. Journal of Applied Econometrics, 31(7):1291-1311.

Anvari, V., Ehlers, N., and Steinbach, R. (2014). A semi-structural approach to estimate South Africa’s potential output. Technical Report 6504, South African Reserve Bank.

Bauer, G. H. and Granziera, E. (2017). Monetary Policy, Private Debt, and Financial Stability Risks. International Journal of Central Banking, 13(3):337-373.

Bayoumi, T. (2001). The morning after: explaining the slowdown in Japanese growth in the 1990s. Journal of International Economics, 53(2):241-259.

Benes, J., Clinton, K., Garcia-Saltos, R., Johnson, M., Laxton, D., Manchev, P., and Matheson, T. (2010). Estimating Potential Output with a Multivariate Filter. IMF Working Paper 10/285, International Monetary Fund.

Berger, H., Dowling, T., Lanau, S., Mrkaic, M., Rabanal, P., and Sanjani, M. T. (2015). Steady as She Goes-Estimating Potential Output During Financial "Booms and Busts". Technical Report 15/233, International Monetary Fund.

Bernanke, B. S., Gertler, M., and Gilchrist, S. (1999). The financial accelerator in a quantitative business cycle framework. In Handbook of Macroeconomics, volume 1, pages 1341-1393. Elsevier.

Bernanke, B. S. and Mihov, I. (1998). Measuring Monetary Policy. The Quarterly Journal of Economics, 113(3):869-902. 
Bernhofer, D., Fernández-Amador, O., Gächter, M., and Sindermann, F. (2014). Finance, Potential Output and the Business Cycle: Empirical Evidence from Selected Advanced and CESEE Economies. Focus on European Economic Integration, (2):52-75.

Blanchard, O. J. and Quah, D. (1989). The Dynamic Effects of Aggregate Demand and Supply Disturbances. American Economic Review, 79(4):655-673.

Bordo, M. D., Redish, A., and Rockoff, H. (2015). Why didn't Canada have a banking crisis in 2008 (or in 1930, or 1907, or ... )? The Economic History Review, 68(1):218-243.

Borio, C. (2014). The financial cycle and macroeconomics: What have we learnt? Journal of Banking \& Finance, 45:182-198.

Borio, C., Disyatat, P., and Juselius, M. (2014a). A parsimonious approach to incorporating economic information in measures of potential output. BIS Working Paper 442, Bank for International Settlements.

Borio, C., Disyatat, P., and Juselius, M. (2017). Rethinking potential output: embedding information about the financial cycle. Oxford Economic Papers, 69(3):655-677.

Borio, C., Drehmann, M., and Tsatsaronis, K. (2014b). Stress-testing macro stress testing: Does it live up to expectations? Journal of Financial Stability, 12:3-15.

Borio, C. and Lowe, P. (2002). Asset prices, financial and monetary stability: exploring the nexus. Technical Report 114, Bank for International Settlements.

Claessens, S., Kose, M. A., and Terrones, M. E. (2012). How do business and financial cycles interact? Journal of International Economics, 87(1):178-190.

Coibion, O., Gorodnichenko, Y., and Ulate, M. (2018). The Cyclical Sensitivity in Estimates of Potential Output. Brookings Papers on Economic Activity, 49(2 (Fall)):343-441. Publisher: Economic Studies Program, The Brookings Institution.

Committee, B. (2010). Guidance for national authorities operating the countercyclical capital buffer. Technical report, Basel, Switzerland.

De Jong, P. (1991). The Diffuse Kalman Filter. The Annals of Statistics, 19(2):1073-1083.

DeJong, D. N. and Whiteman, C. H. (1993). Estimating Moving Average Parameters: Classical Pileups and Bayesian Posteriors. Journal of Business \& Economic Statistics, 11(3):311-317.

DeLong, E. R., DeLong, D. M., and Clarke-Pearson, D. L. (1988). Comparing the Areas under Two or More Correlated Receiver Operating Characteristic Curves: A Nonparametric Approach. Biometrics, 44(3):837-845.

Detken, C., Peltonen, T. A., Schudel, W., and Behn, M. (2013). Setting countercyclical capital buffers based on early warning models: would it work? Technical Report 1604, European Central Bank. 
Edge, R. M. and Meisenzahl, R. R. (2011). The Unreliability of Credit-to-GDP Ratio Gaps in Real Time: Implications for Countercyclical Capital Buffers. International Journal of Central Banking, 7(4):261-298.

Ermolaev, I., Juillard, M., Carabenciov, I., Freedman, C., Laxton, D., Kamenik, O., and Korshunov, D. (2008). A Small Quarterly Projection Model of the US Economy. IMF Working Paper 08/278, International Monetary Fund.

Felipe, J., Sotocinal, N., and Bayudan-Dacuycuy, C. (2015). The Impact of Financial Factors on the Output Gap and Estimates of Potential Output Growth. Technical Report 457, Asian Development Bank.

Gali, J. (1999). Technology, Employment, and the Business Cycle: Do Technology Shocks Explain Aggregate Fluctuations? American Economic Review, 89(1):249-271.

Grant, A. L. and Chan, J. C. C. (2017). Reconciling output gaps: Unobserved components model and Hodrick-Prescott filter. Journal of Economic Dynamics and Control, 75:114-121.

Grintzalis, I., Lodge, D., and Manu, A.-S. (2017). The implications of global and domestic credit cycles for emerging market economies: measures of finance-adjusted output gaps. Technical Report 2034, European Central Bank.

Haltom, R. C. (2013). Why Was Canada Exempt from the Financial Crisis? Econ Focus, (4Q):22-25.

Harvey, A. C. and Jaeger, A. (1993). Detrending, stylized facts and the business cycle. Journal of Applied Econometrics, 8(3):231-247.

Hume, M. and Sentance, A. (2009). The global credit boom: Challenges for macroeconomics and policy. Journal of International Money and Finance, 28(8):1426-1461.

Jordà, Ò., Schularick, M., and Taylor, A. M. (2013). When Credit Bites Back. Journal of Money, Credit and Banking, 45(s2):3-28.

Kilian, L. and Lütkepohl, H. (2017). Structural Vector Autoregressive Analysis. Cambridge University Press, Cambridge New York, NY.

Kim, C.-J. and Kim, J. (2013). The 'Pile-up Problem' in Trend-Cycle Decomposition of Real GDP: Classical and Bayesian Perspectives. Technical Report 51118, University Library of Munich, Germany.

King, R. G., Plosser, C. I., Stock, J. H., and Watson, M. W. (1991). Stochastic Trends and Economic Fluctuations. The American Economic Review, 81(4):819-840.

King, R. G. and Rebelo, S. T. (1993). Low frequency filtering and real business cycles. Journal of Economic Dynamics and Control, 17(1):207-231.

Kiyotaki, N. and Moore, J. (1997). Credit Cycles. Journal of Political Economy, 105(2):211-248. 
Krupkina, A., Deryugina, E., and Ponomarenko, A. (2015). Estimating Sustainable Output Growth in Emerging Market Economies. Comparative Economic Studies, 57(1):168-182.

Kuttner, K. N. (1994). Estimating Potential Output as a Latent Variable. Journal of Business \& Economic Statistics, 12(3):361-368.

Lang, J. H., Izzo, C., Fahr, S., and Ruzicka, J. (2019). Anticipating the bust: a new cyclical systemic risk indicator to assess the likelihood and severity of financial crises. Technical Report 219, European Central Bank. Occasional Paper Series.

Maliszewski, W. and Zhang, L. (2015). China’s Growth; Can Goldilocks Outgrow Bears? Technical Report 15/113, International Monetary Fund.

Melolinna, M. and Tóth, M. (2019). Output gaps, inflation and financial cycles in the UK. Empirical Economics, 56(3):1039-1070.

Mishkin, F. S. (2007). Estimating potential output: a speech at the Conference on Price Measurement for Monetary Policy, Federal Reserve Bank of Dallas, Dallas, Texas, May 24, 2007. Technical Report 299, Board of Governors of the Federal Reserve System (U.S.).

Odor, L. and Kucserova, J. J. (2014). Finding Yeti: More robust estimates of output gap in Slovakia. Technical Report WP 1/2014, Research Department, National Bank of Slovakia.

Okun, A. M. (1962). Potential GNP \& Its Measurement and Significance. American Statistical Association, Proceedings of the Business and Economics Statistics Section, pages 98-104.

Orphanides, A. and Norden, S. v. (2002). The Unreliability of Output-Gap Estimates in Real Time. The Review of Economics and Statistics, 84(4):569-583.

Pepe, M. S. (2003). The Statistical Evaluation of Medical Tests for Classification and Prediction. Oxford Statistical Science Series. Oxford University Press, Oxford, New York.

Rosenberg, B. (1973). Random Coefficients Models: The Analysis of a Cross Section of Time Series by Stochastically Convergent Parameter Regression. In NBER Chapters, pages 399-428. National Bureau of Economic Research, Inc.

Rünstler, G. and Vlekke, M. (2018). Business, housing, and credit cycles. Journal of Applied Econometrics, 33(2):212-226.

Schularick, M. and Taylor, A. M. (2012). Credit Booms Gone Bust: Monetary Policy, Leverage Cycles, and Financial Crises, 1870-2008. American Economic Review, 102(2):1029-1061.

Shephard, N. (1993). Maximum Likelihood Estimation of Regression Models with Stochastic Trend Components. Journal of the American Statistical Association, 88(422):590-595.

Stock, J. H. (1994). Unit roots, structural breaks and trends. In Handbook of Econometrics, volume 4, pages 2739-2841. Elsevier. 
Stock, J. H. and Watson, M. W. (1998). Median Unbiased Estimation of Coefficient Variance in a Time-Varying Parameter Model. Journal of the American Statistical Association, 93(441):349358.

White, W. R. (2006). Is price stability enough? Technical Report 205, Bank for International Settlements.

Woodford, M. (2003). Interest and prices : foundations of a theory of monetary policy / Michael Woodford. Princeton University Press, Princeton, N.J. : Woodstock. Includes bibliographical references (p. 747-764) and index.

Wooldridge, J. M. (2005). Simple solutions to the initial conditions problem in dynamic, nonlinear panel data models with unobserved heterogeneity. Journal of Applied Econometrics, 20(1):39-54. 


\section{Appendix}

\section{A Data sources}

Table 4: Data sources

\begin{tabular}{|c|c|c|}
\hline Variable & Main sources & Other sources \\
\hline $\begin{array}{l}\text { Total Gross Domestic Product in } \\
\text { Constant Prices }\end{array}$ & $\begin{array}{l}\text { OECD, "Main Economic Indicators - } \\
\text { complete database", Main Economic } \\
\text { Indicators (database), } \\
\text { http://dx.doi.org/10.1787/data-00052-en }\end{array}$ & $\begin{array}{l}\text { For Canada, Germany, Spain, Italy and } \\
\text { Japan: GDP is computed with GDP growth } \\
\text { rate from the OECD (Sources : Leading } \\
\text { Indicators OECD: Reference Series: Gross } \\
\text { Domestic Product). } \\
\text { For the United States and the United } \\
\text { Kingdom, GDP is in chained } 2000 \text { National } \\
\text { Currency Units. }\end{array}$ \\
\hline $\begin{array}{l}\text { Consumer Price Index of All } \\
\text { Items ; Index } 2010\end{array}$ & $\begin{array}{l}\text { OECD, "Main Economic Indicators - } \\
\text { complete database", Main Economic } \\
\text { Indicators (database), } \\
\text { http://dx.doi.org/10.1787/data-00052-en }\end{array}$ & \\
\hline Rate of Capacity utilisation & $\begin{array}{l}\text { OECD, "Main Economic Indicators - } \\
\text { complete database", Main Economic } \\
\text { Indicators } \\
\text { (database),http://dx.doi.org/10.1787/data- } \\
\text { 00052-en }\end{array}$ & $\begin{array}{l}\text { For Canada, Industrial Capacity utilisation } \\
\text { rates are from Statistics Canada. } \\
\text { For Japan, data are "Operating Ratio index" } \\
\text { from "Indices of Industrial Production, } \\
\text { Ministry of Economy, Trade and Industry, } \\
\text { Statistics". }\end{array}$ \\
\hline $\begin{array}{l}\text { Unemployment Rate; Aged } \\
\text { 15-74: All Persons }\end{array}$ & OECD Economic Outlook database & $\begin{array}{l}\text { For Germany, data are from OECD, "Main } \\
\text { Economic Indicators - complete database", } \\
\text { Main Economic Indicators } \\
\text { (database),http://dx.doi.org/10.1787/data- } \\
\text { 00052-en }\end{array}$ \\
\hline $\begin{array}{l}\text { Total credit to private } \\
\text { non-financial sector, all sectors, } \\
\text { adjusted for breaks }\end{array}$ & BIS total credit statistics & \\
\hline $\begin{array}{l}\text { Real Residential Property Prices; } \\
\text { Long Series; Index } 1995\end{array}$ & $\begin{array}{l}\text { National sources, BIS Residential Property } \\
\text { Price database }\end{array}$ & \\
\hline
\end{tabular}

\section{B Dynamic multivariate filter}

The model is as follows: 


$$
\left\{\begin{array}{l}
\hat{y}_{t}=\alpha_{1} \hat{y}_{t-1}+\gamma^{\prime} z_{t}+\varepsilon_{t}^{\hat{y}} \\
y_{t}^{\star}=y_{t-1}^{\star}+g_{t}^{y}+\varepsilon_{t}^{y^{\star}} \\
g_{t}^{y}=\alpha_{2} \bar{g}^{y}+\left(1-\alpha_{2}\right) g_{t-1}^{y}+\varepsilon_{t}^{g y}
\end{array}\right.
$$

where the notations are similar as in model A (section 2.1). $\bar{g}^{y}$ is calibrated as the sample average growth rate. $\varepsilon_{t}^{\hat{y}}, \varepsilon_{t}^{y^{\star}}$ and $\varepsilon_{t}^{g y}$ are i.i.d. error terms. To achieve stationarity, we apply the same pretransformation technique on the additional variables $z_{t}$ as in the extended HP filter.

This model is arguably more flexible than the extended HP filter, but the increased number of parameters to be estimated makes the identification less straightforward. In particular, since the scaling factor is now estimated instead of calibrated, the "pile-up problem" becomes a major issue. To overcome the difficulties in estimating the model, we use Bayesian techniques (see DeJong and Whiteman (1993); Kim and Kim (2013)). The priors and the posterior estimates are presented in Table 5. Results are shown in Figure 5.

Figure 5: Output gap estimates: dynamic multivariate filter
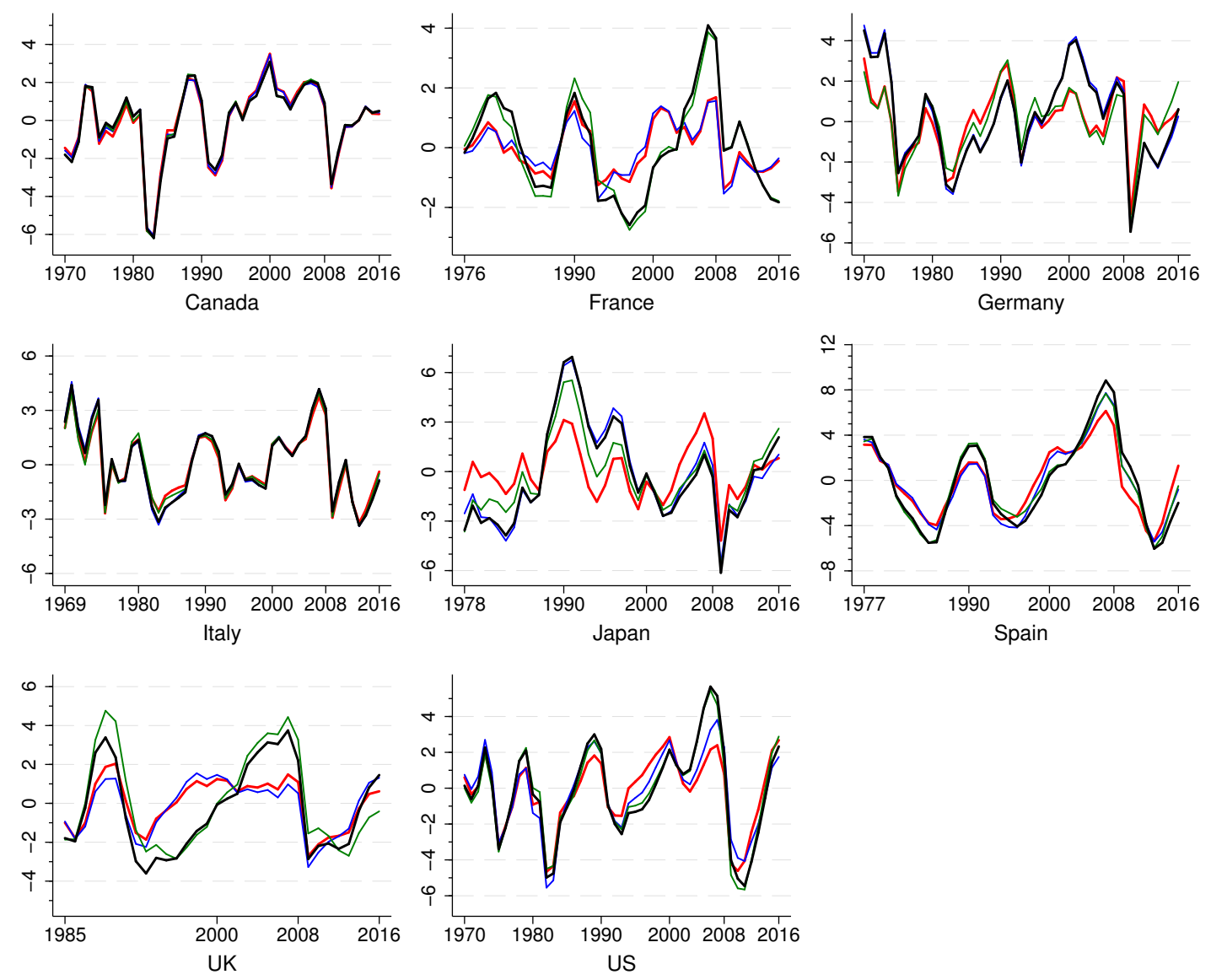

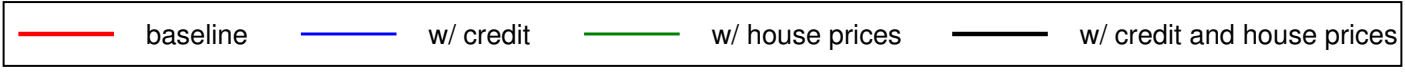




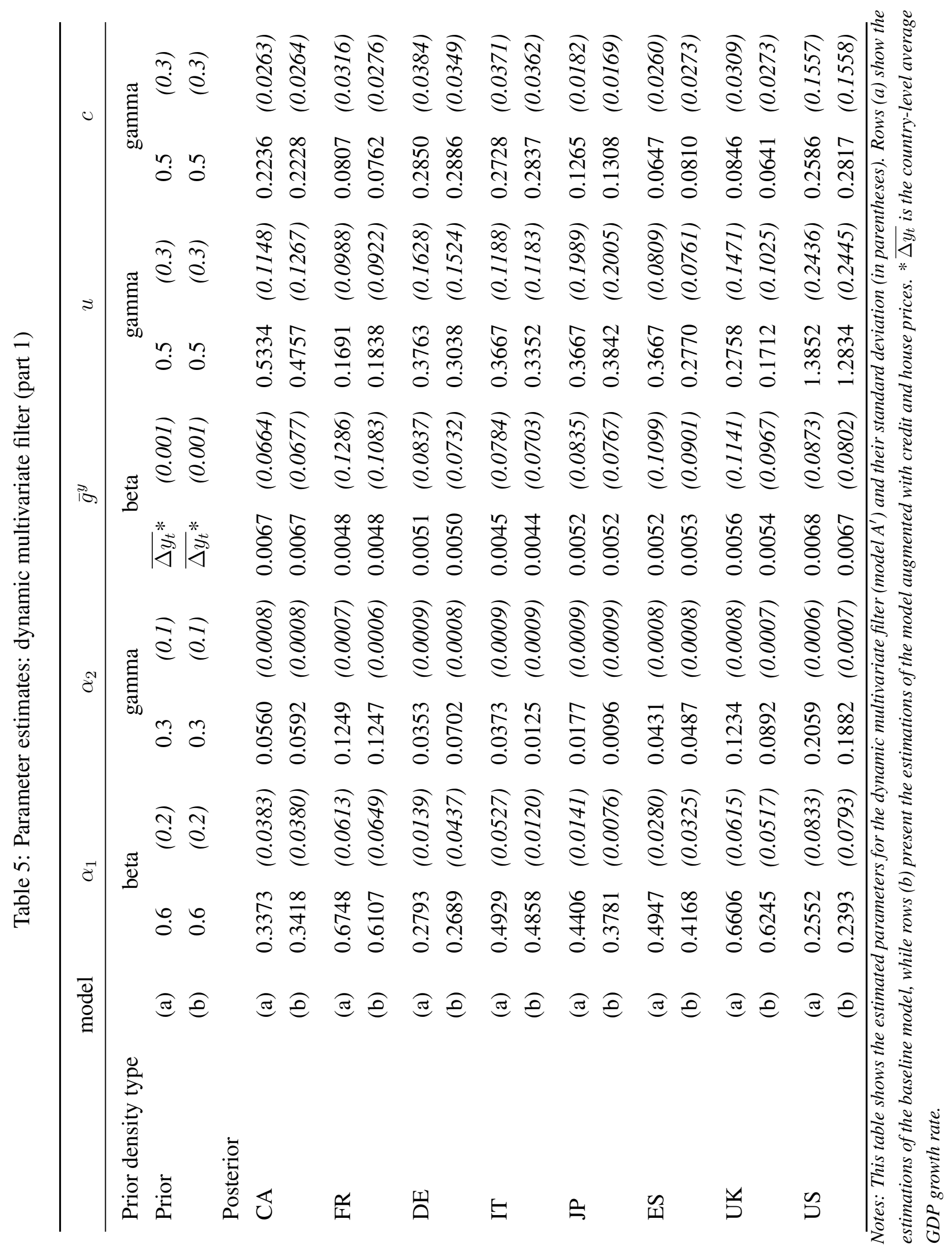




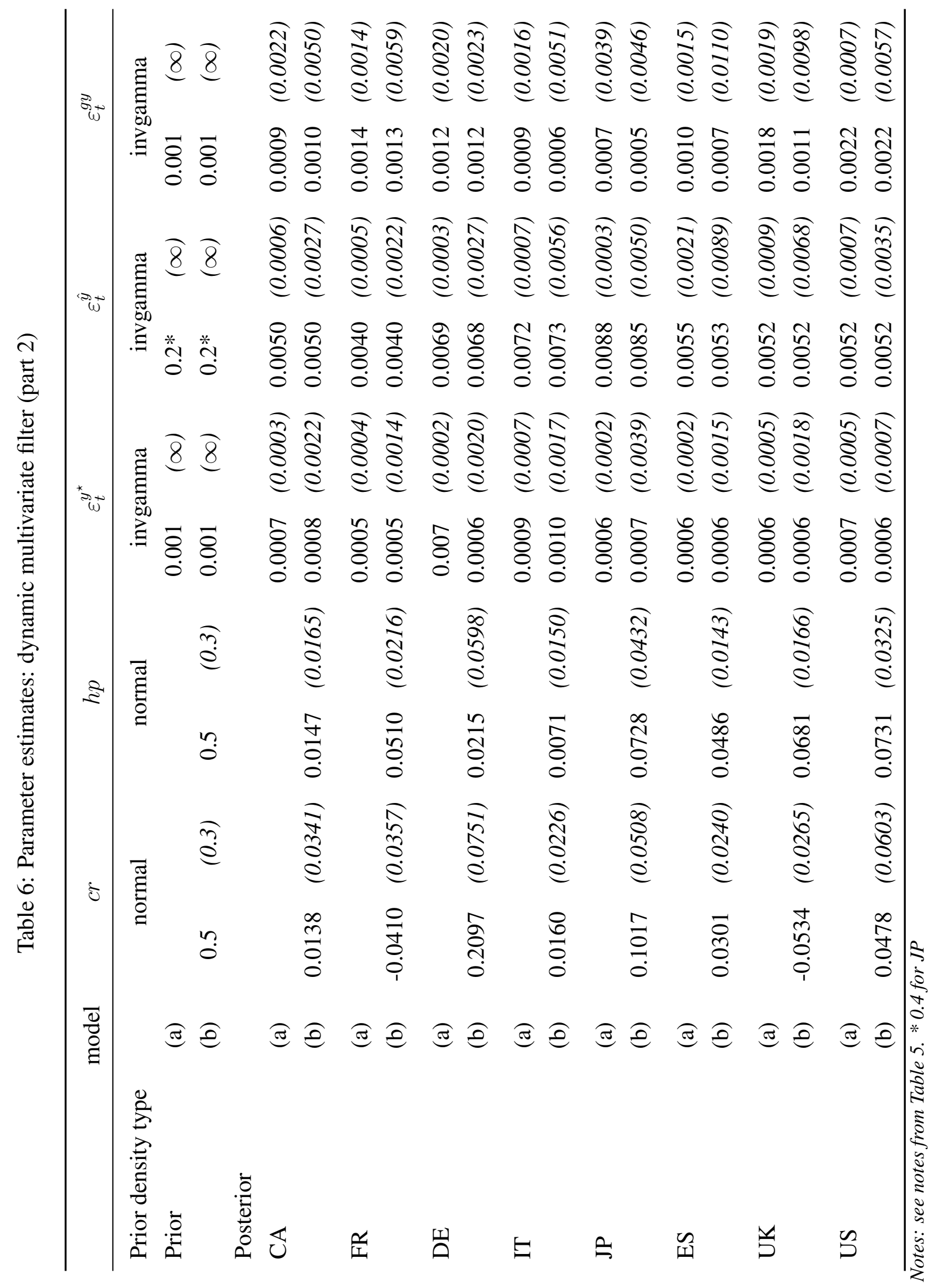




\section{Parameter estimates}

For reasons of brevity reasons, only the estimated parameters of the baseline (model a) and the most complete model with both credit and house prices included (model b) are shown. The other estimation results are available from the authors upon request.

Table 7: Parameter estimates: extended Hodrick-Prescott filter

\begin{tabular}{lcccccccccc}
\hline & model & \multicolumn{2}{c}{$u$} & \multicolumn{2}{c}{$c$} & \multicolumn{2}{c}{$c r$} & & \multicolumn{2}{c}{$h p$} \\
\hline CA & (a) & -1.01 & $(0.10)$ & 0.24 & $(0.02)$ & & & & \\
& (b) & -0.97 & $(0.11)$ & 0.25 & $(0.02)$ & 0.04 & $(0.03)$ & -0.01 & $0.02)$ \\
FR & (a) & -0.63 & $(0.14)$ & 0.26 & $(0.03)$ & & & & \\
& (b) & -0.48 & $(0.16)$ & 0.21 & $(0.03)$ & -0.01 & $(0.04)$ & 0.08 & $(0.02)$ \\
DE & (a) & -1.17 & $(0.20)$ & 0.32 & $(0.03)$ & & & & \\
& (b) & -0.51 & $(0.21)$ & 0.38 & $(0.03)$ & 0.24 & $(0.07)$ & 0.06 & $(0.05)$ \\
IT & (a) & -0.89 & $(0.16)$ & 0.45 & $(0.03)$ & & & & \\
& (b) & -0.66 & $(0.18)$ & 0.47 & $(0.03)$ & 0.01 & $(0.03)$ & 0.05 & $(0.02)$ \\
JP & (a) & -1.35 & $(0.41)$ & 0.16 & $(0.02)$ & & & & \\
& (b) & -0.99 & $(0.43)$ & 0.15 & $(0.02)$ & 0.03 & $(0.08)$ & 0.22 & $(0.06)$ \\
ES & (a) & -0.60 & $(0.09)$ & 0.06 & $(0.03)$ & & & & \\
& (b) & -0.53 & $(0.10)$ & 0.06 & $(0.03)$ & -0.05 & $(0.04)$ & 0.05 & $(0.02)$ \\
UK & (a) & -1.27 & $(0.18)$ & 0.15 & $(0.04)$ & & & & \\
& (b) & -1.08 & $(0.21)$ & 0.08 & $(0.04)$ & -0.04 & $(0.04)$ & 0.08 & $(0.02)$ \\
US & (a) & -0.73 & $(0.15)$ & 0.31 & $(0.04)$ & & & & \\
& (b) & -0.37 & $(0.17)$ & 0.35 & $(0.04)$ & 0.12 & $(0.04)$ & 0.04 & $(0.02)$ \\
\hline
\end{tabular}

Notes: This table shows the estimated parameters for the extended HP model and their standard deviation (in parentheses). Rows (a) show the estimations of the baseline model, while rows $(b)$ present the estimations of the model augmented with credit and house prices. 


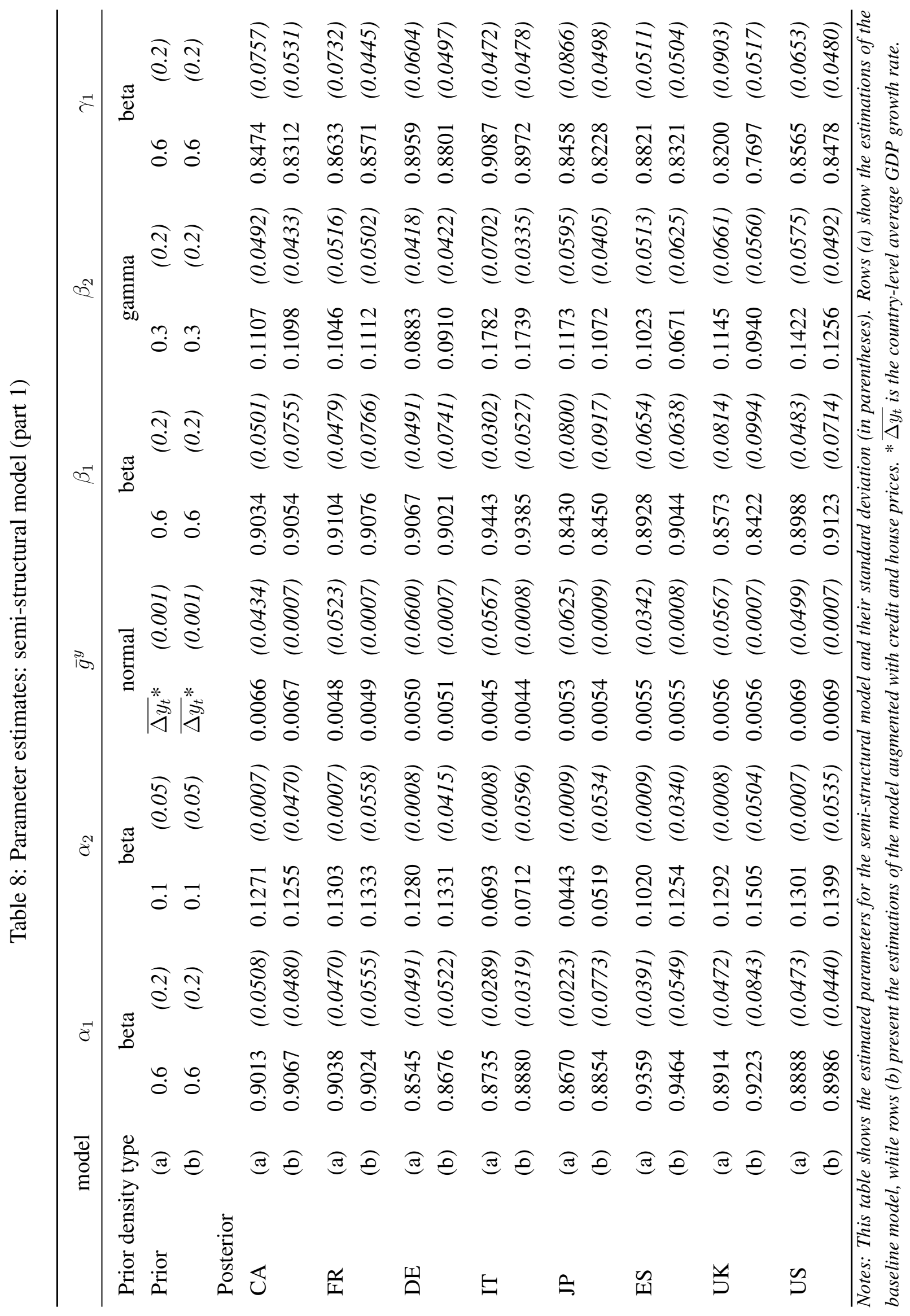




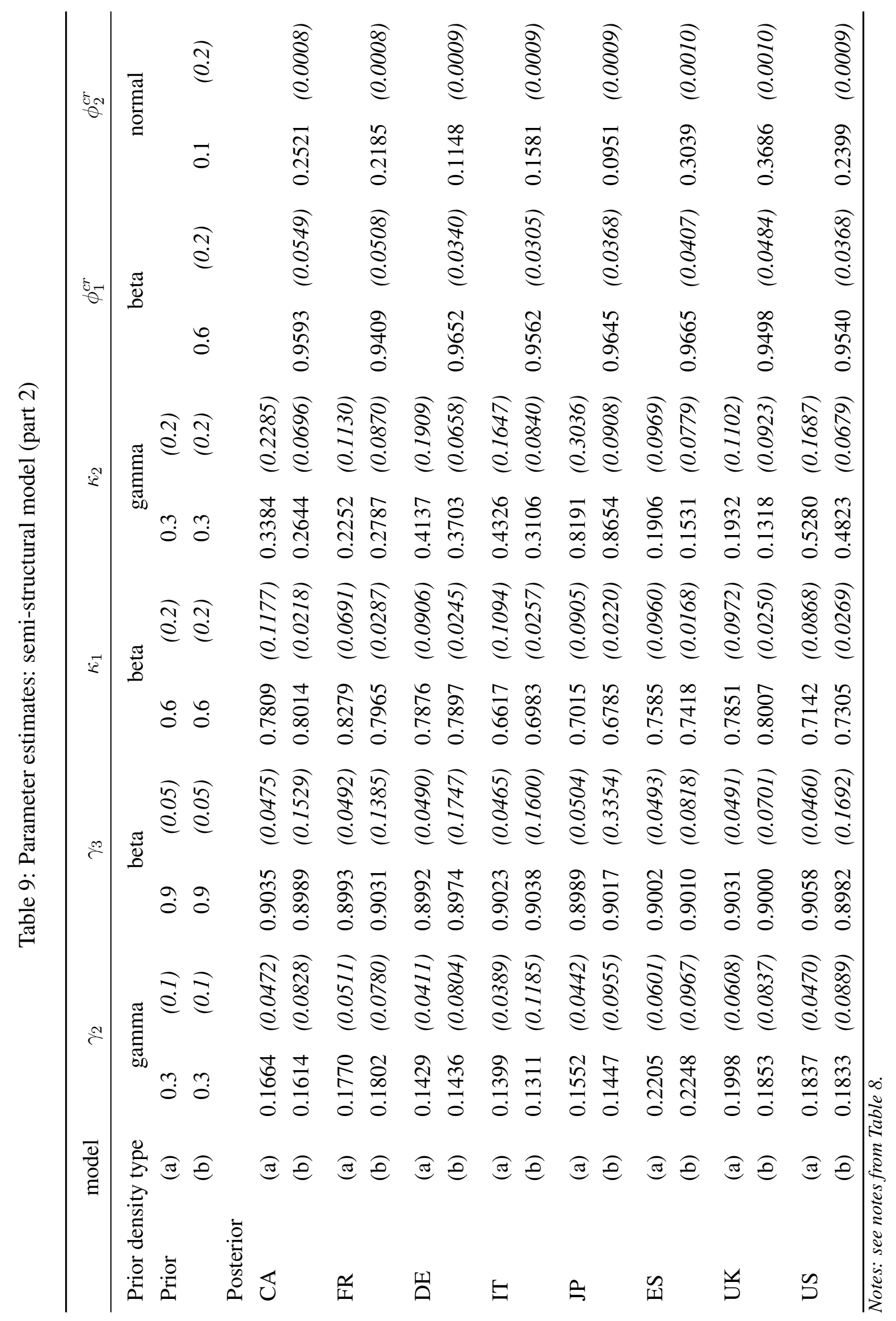




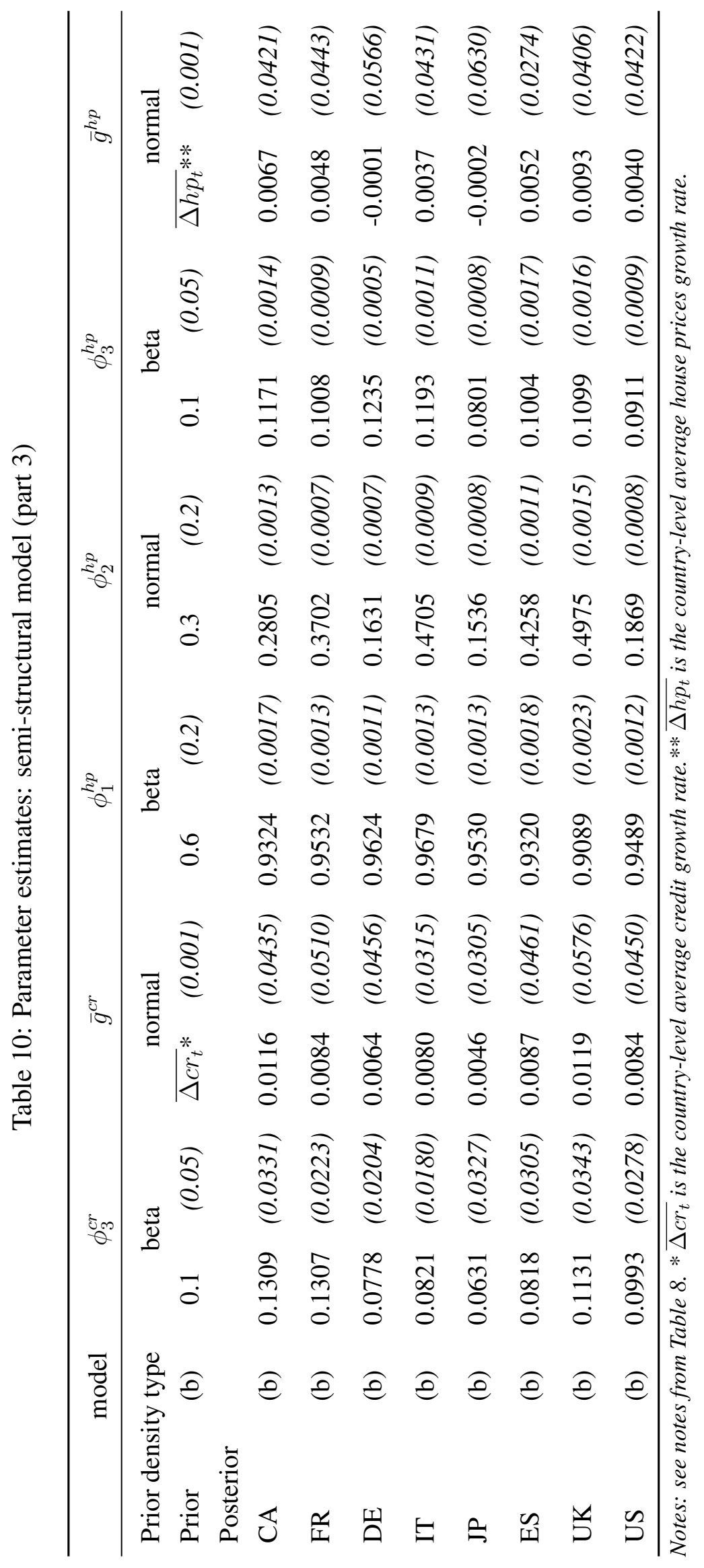




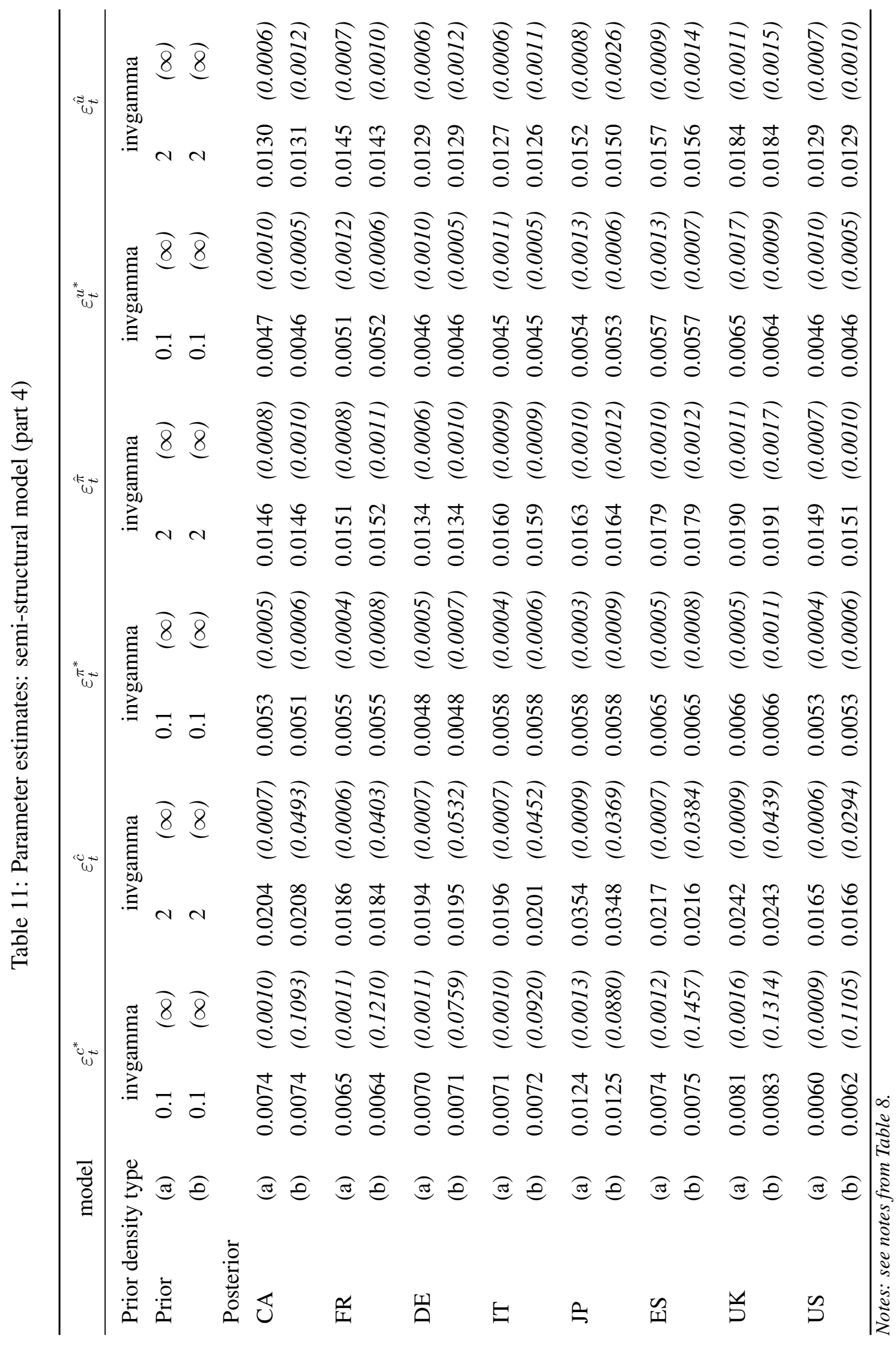




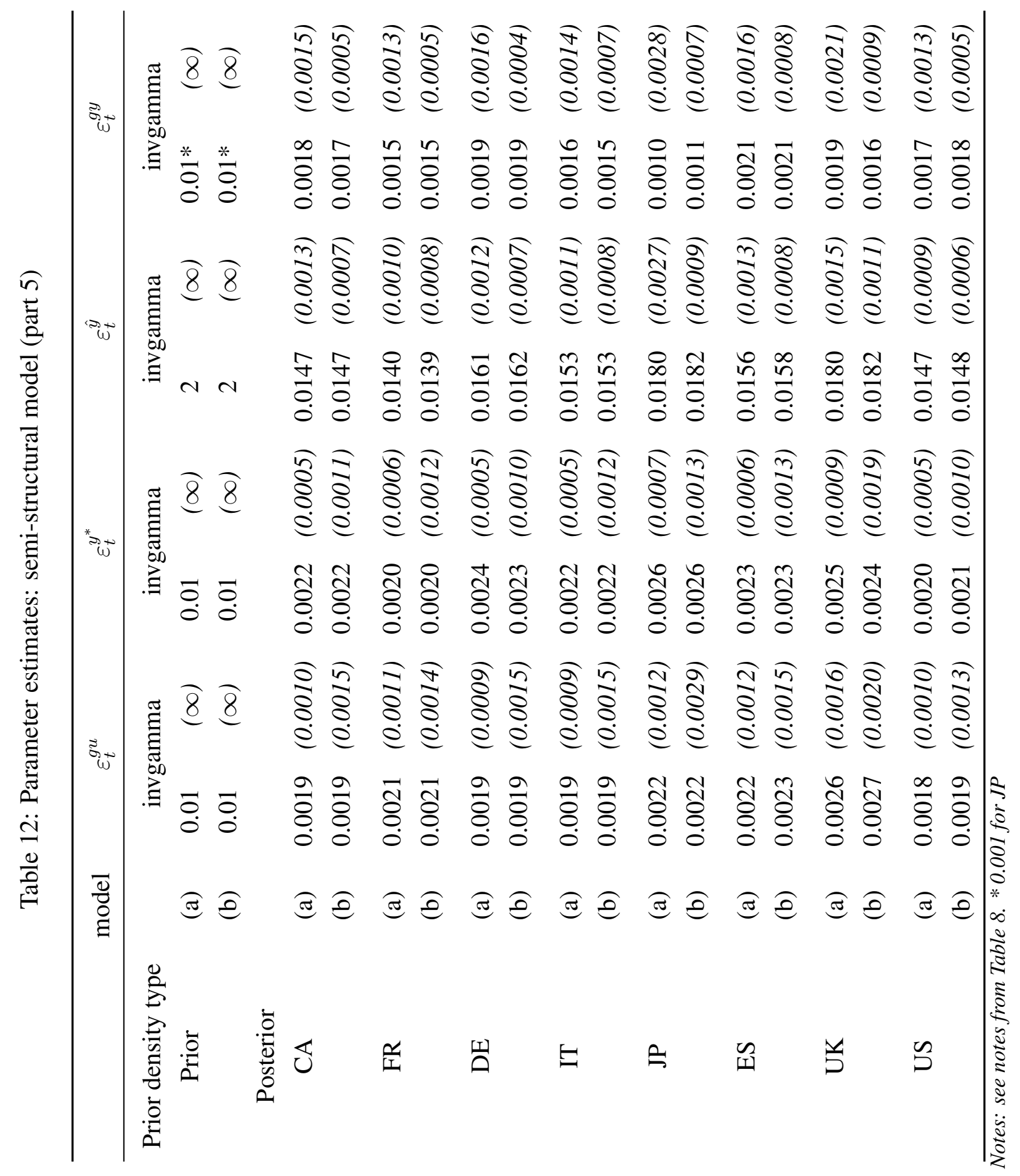




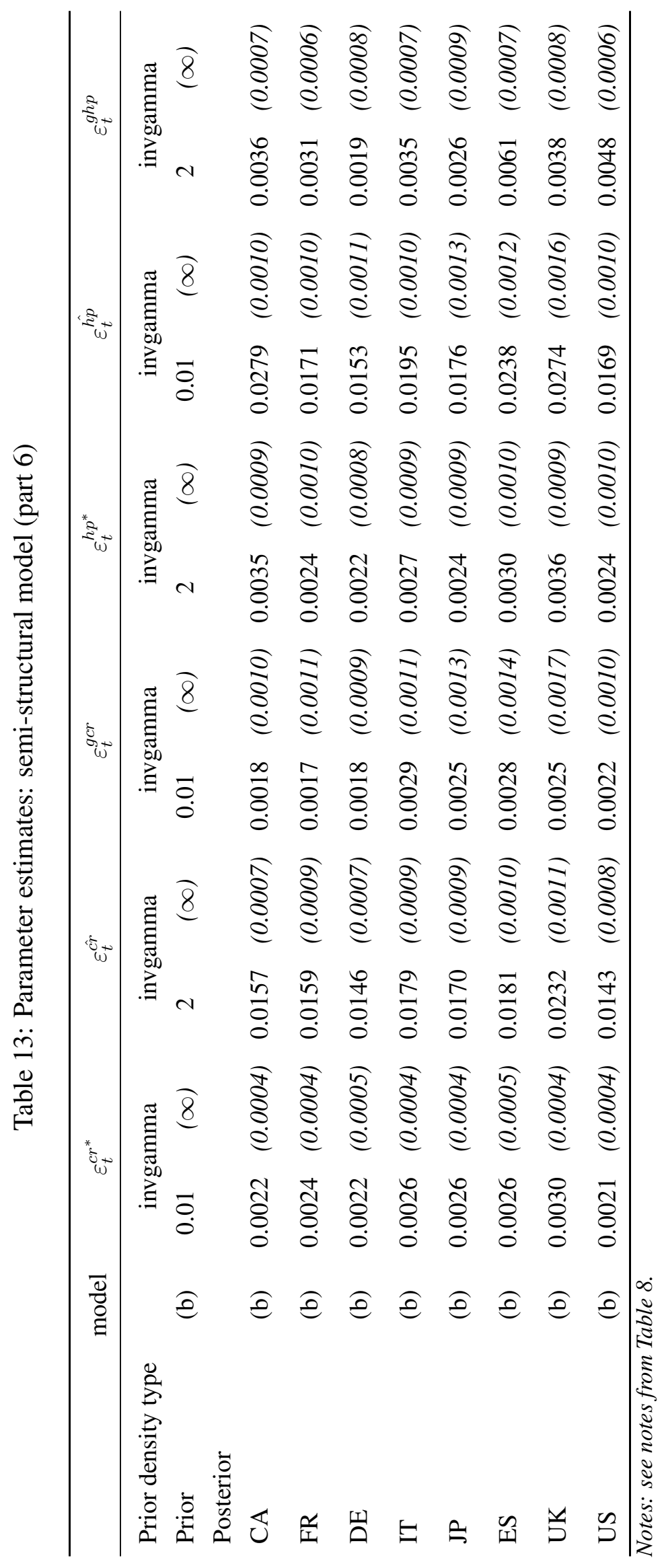




\section{List of recessions}

Recession is defined as two consecutive quarters of negative seasonally adjusted GDP growth. "Mild recessions" are those which last less than a year and results in a drop in GDP of less than 1 per cent. The list of recessions in our sample is (mild recessions are in parentheses):

- CA: (1980q2-1980q3), 1981q3-1982q4, 1990q2-1991q1, 2008q4-2009q2, (2015q1-2015q2)

- FR: 1992q2-1993q1, 2008q2-2009q2

- DE: 1974q4-1975q2, 1980q2-1980q4, 1982q2-1982q3, (1991q2-1992q3), 1992q2-1993q1, 1995q4-1996q1, 2002q4-2003q1, 2008q2-2009q1, (2012q4-2013q1)

- IT: 1974q4-1975q2, 1977q2-1977q3, 1982q2-1982q4, 1992q2-1993q3, (2001q2-2003q2), (2007q3-2007q4), 2008q2-2009q2, 2011q3-2013q1

- JP: 1993q2-1993q3, 1998q1-1998q2, 2001q2-2001q4, (2007q2-2007q3), 2008q2-2009q1, 2010q4-2011q2, (2012q2-2012q3), 2014q2-2014q3

- ES: (1978q3-1979q1), (1981q1-1981q2), 1992q4-1993q2, 2008q3-2009q4, 2011q1-2013q3

- UK: 1990q3-1991q3, 2008q2-2009q2

- US: 1974q3-1975q1, 1980q2-1980q3, 1981q4-1982q1, 2008q3-2009q2

The list of recessions is consistent with general knowledge about economic and financial turmoil in these countries in our sample. For the US, the main recessions identified by the $\mathrm{NBER}^{20}$ are listed: the oil crisis of 1974; a relatively short recession in 1980; the recession caused by the sharp increase in oil prices following the Iranian revolution and the tight monetary policy in the US in 1981; and the Great Financial Crisis of 2008-2009. The NBER's recession following the collapse of the speculative dot-com bubble in 2001 is excluded from our analysis because it did not last 2 consecutive quarters. As for the Euro Area countries, the financial recessions identified by Lang et al. (2019) are included in our list. Other recessions which do not result from systemic financial crises are: the recessions in the 1980s and the 1990s in DE; the recessions in the 1970s and the 1980s in IT; and the recession in the 1990s in ES. All recessions listed in Lang et al. (2019) for CA, JP and the UK are also included in our list.

\section{E Distance between the time of entry into recession and the closest peak}

A peak in the output gap is identified if $\hat{y}_{i t}>\hat{y}_{i t+l}, \forall l \in\{-12, \ldots,-1,1, \ldots, 12\}$. The histogram of the distances between the time of entry into recession and the closest peak is plotted in Figure 6 . We

\footnotetext{
${ }^{20}$ See https://www.nber.org/cycles/.
} 
disregard the observations in which the entry into recession precedes the closest peak by more than four quarters ( 15 cases out of the total of 204 distance measures).

Figure 6: Distance between the time of entry into recession and the closest peak (all countries and models)

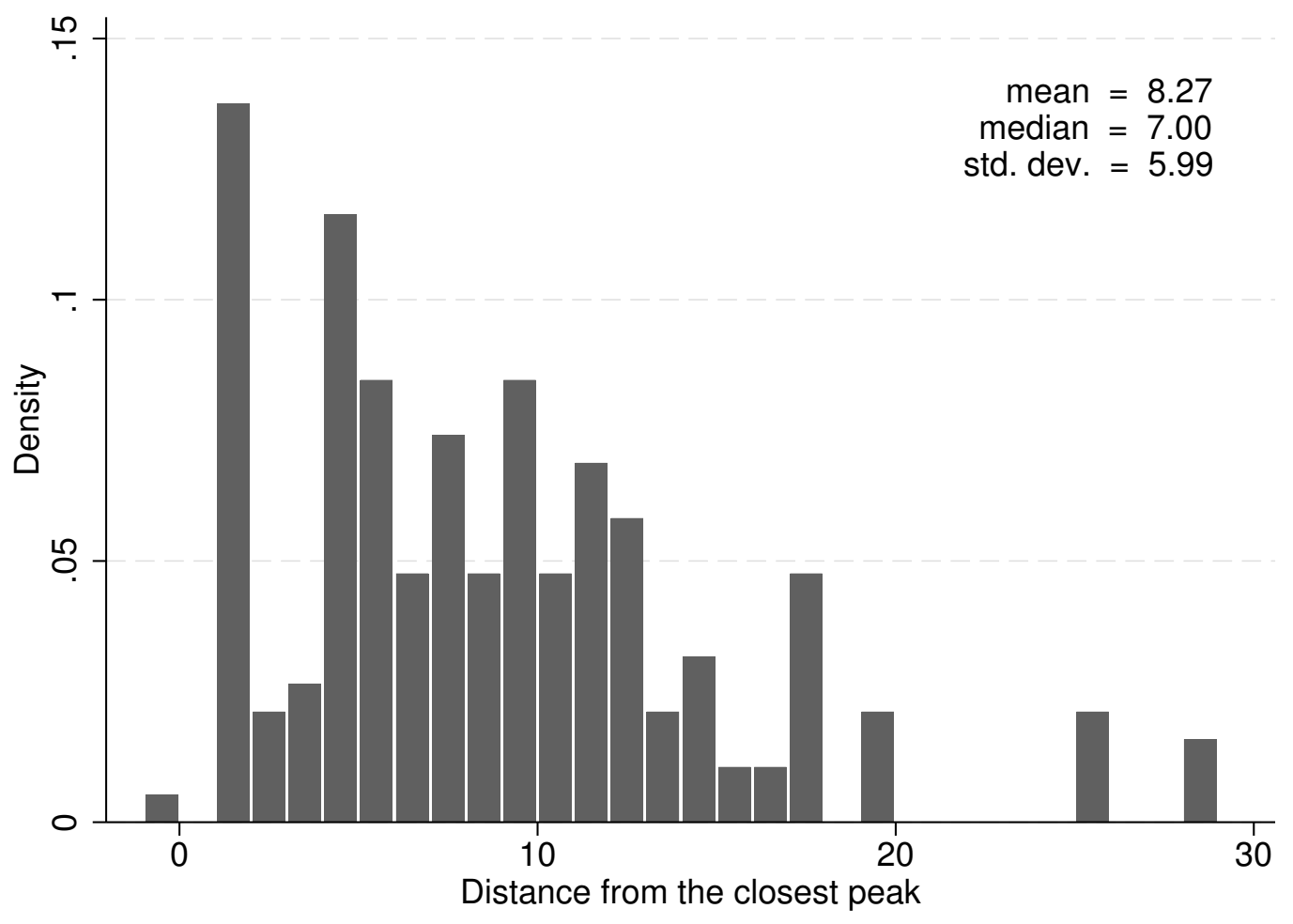

